\title{
IQGAP3 promotes cancer proliferation and metastasis in high-grade serous ovarian cancer
}

\author{
SAMINA DONGOL ${ }^{1,2}$, QING ZHANG ${ }^{1,2}$, CHUNPING QIU $^{1,2}$, CHENGGONG SUN $^{1,2}$, \\ ZHIWEI ZHANG ${ }^{1,2}$, HUAN WU ${ }^{1,2}$ and BEIHUA KONG ${ }^{1,2}$ \\ ${ }^{1}$ Department of Obstetrics and Gynecology; ${ }^{2}$ Key Laboratory of Gynecologic Oncology of \\ Shandong, Qilu Hospital of Shandong University, Ji'nan, Shandong 250012, P.R. China
}

Received November 25, 2019; Accepted April 22, 2020

DOI: $10.3892 / \mathrm{ol} .2020 .11664$

\begin{abstract}
Ovarian cancer is a type of gynecological cancer with the highest mortality rate worldwide. Due to a lack of effective screening methods, most cases are diagnosed at later stages where the survival rates are poor. Thus, it is termed a 'silent killer' and is the most lethal of all the malignancies in women. IQ motif containing GTPase Activating Protein 3 (IQGAP3) is a member of the Rho family of GTPases, and plays a crucial role in the development and progression of several types of cancer. The aim of the present study was to investigate the oncogenic functions and mechanisms of IQGAP3 on the proliferation and metastasis of high-grade serous ovarian cancer (HGSOC). Therefore, the expression levels of IQGAP3 in HGSOC and normal tissue samples were compared, and IQGAP3 knockdown was performed to examine its functional role using various in vitro and in vivo experiments. It was demonstrated that the expression of IQGAP3 was upregulated in HGSOC tissues compared with the healthy tissues; this differential expression was also observed in the ovarian cancer cell lines. Functional experimental results suggested that IQGAP3 silencing significantly reduced proliferation, migration and invasion in ovarian cancer cell lines. Moreover, in vivo experimental findings validated the in vitro results, where the tumorigenic and metastatic capacities of IQGAP3-silenced cells were significantly lower in the nude mice compared with the mice implanted with the control cells. Furthermore, knockdown of IQGAP3 resulted in increased apoptosis, and the effects of IQGAP3 expression on various epithelial-mesenchymal transition markers were identified, suggesting a possible mechanism associated with the role of IQGAP3 in metastasis. The effect of IQGAP3 silencing on chemosensitivity towards olaparib was also assessed.
\end{abstract}

Correspondence to: Professor Beihua Kong, Department of Obstetrics and Gynecology, Qilu Hospital of Shandong University, 107 Wenhua West, Ji'nan, Shandong 250012, P.R. China

E-mail: qlkongbeihua@yahoo.com

Key words: IQ motif containing GTPase activating protein 3, ovarian cancer, proliferation, metastasis, cell division cycle 42
Collectively, the present results indicated that IQGAP3 is a potential diagnostic and prognostic marker, and a putative therapeutic target of HGSOC.

\section{Introduction}

Ovarian cancer is one of the most malignant types of gynecological cancer, and is the 11th most common type of cancer among women, as well as the 5th leading cause of cancerassociated mortality in the USA (1). In addition, ovarian cancer is the leading cause of gynecological malignancy-associated mortality $(1,2)$. The American Cancer Society estimated there were 22,530 new cases of ovarian cancer and 13,980 mortalities from ovarian cancer in the USA in 2019 (1). Furthermore, the incidence of new ovarian cancer cases has been decreasing on average by $2.5 \%$ each year in the past decade; however, the overall survival rate has not improved in recent years (2). The current 5-year survival rate for all the stages of ovarian cancer cases in the US is approximately $47 \%$ (1). However, approximately $60 \%$ of the new cases are diagnosed at advanced stages, and in those cases, the 5-year survival rate is only $29 \%$ (1). Moreover, there is a high rate of recurrence even after aggressive multimodal treatment, which further worsens the prognosis (3).

Ovarian cancer belongs to a group of heterogeneous tumors that arise spontaneously largely from the ovaries, but may evolve from various other potential sources (4-6). In addition, ovarian cancer can be morphologically classified into epithelial and non-epithelial types, of which $80-90 \%$ of all ovarian cancer cases are epithelial type (5). Based on their aggressiveness, epithelial ovarian cancers (EOCs) are further subdivided into high- and low-grade categories; or morphologically, they are subdivided into serous, endometrioid, mucinous and clear cell varieties $(7,8)$. High-grade serous ovarian cancer (HGSOC) accounts for $50-60 \%$ of all ovarian neoplasms (8). Furthermore, advanced HGSOC accounts for approximately 50\% of all EOCs (7-9), but the precise etiological factors underlying ovarian cancer have not been fully elucidated. However, hereditary susceptibility is considered an important risk factor, as approximately $35 \%$ of HGSOC cases harbor a germline mutation of the tumor suppressor genes Breast cancer type 1 susceptibility protein (BRCA1) or BRCA2 (10). 
The current therapeutic measure used to treat ovarian cancer is a multimodal regimen, and a combination of platinum and paclitaxel is used as the primary chemotherapeutic regimen (11). However, the relapse rate remains high due to chemoresistance (12). Poly ADP-ribose polymerase inhibitor (PARPi) has been introduced as a promising therapeutic agent to improve the prognosis of HGSOC (13). Olaparib is the most commonly used PARPi, and exhibits favorable outcomes in lowering disease progression and mortality rates (14). Moreover, olaparib has been approved by the Food and Drug Administration (FDA) as the first monotherapy to combat advanced epithelial ovarian cancer cases harboring germline $B R C A$ mutations (15).

IQ motif containing GTPase Activating Proteins (IQGAPS) are a family of GTPase activating proteins, which have been evolutionarily conserved from yeast to mammals $(16,17)$. In a review by Hedman et al (18), the varied functions of IQGAPs, in addition to serving as scaffolding proteins are discussed. In total, three members of the IQGAP family have been described in humans (18). Furthermore, all three members are equipped with four IQ motifs and a Ras GTPase-activating protein (GAP)-related domain (18); the GAP-related domain of IQGAPS mediates its binding to the Rho family of GTPases (19). A member of the Rho family of GTPases, Cell Division Cycle 42 (CDC42) has been revealed to serve critical roles in cell proliferation, survival, adhesion and migration, and is correlated with a less favorable prognosis in various types of cancer (20-23). Of the three IQGAP family members, $I Q G A P I$ has been reported to play a synergistic role in cancer progression and aid in cellular motility (24-26). However, $I Q G A P 2$ exhibits a tumor suppressive function (26). Moreover, $I Q G A P 3$ is hypothesized to be involved in the proliferation of epithelial cells (27), and is a novel member of the IQGAP family, which was discovered in 2007 (28). IQGAP3 is located on chromosome 1 at 1q21.3 loci and has been reported to act as an oncogene in several types of cancer (29-35). Furthermore, $I Q G A P 3$ is a transmembrane protein, and has been speculated to be a potential therapeutic target (35).

The present study aimed to analyze the differential expression of IQGAP3 in HGSOC and healthy tissues, and the effect of IQGAP3 knockdown on various functional processes, such as cell proliferation, migration, invasion and apoptosis, to determine whether IQGAP3 could serve as a potential oncogenic prognostic and therapeutic target for patients with HGSOC.

\section{Materials and methods}

Tissue samples. A total of 149 ovarian cancer tissue samples (patient age range, 34-79 years; median age, 56 years) and 64 healthy fallopian tube epithelial tissues (patient age range, 26-74 years; median age, 47 years) with detailed clinical information were collected from the Pathology Department at Qilu Hospital of Shandong University (Ji'nan, China) between January 2005 and January 2015. All the malignant samples were diagnosed in accordance with the International Federation of Gynecology and Obstetrics criteria (36). The healthy samples were collected from patients who underwent surgery for benign conditions. Signed consents were collected from all the patients and the study was approved by the Ethics Committee of Qilu Hospital of Shandong University.

Survival analysis was performed on datasets from the Gene Expression Omnibus (GEO) database, including 523 patients for overall survival analysis using datasets GSE18520 (37), GSE26193 (38), GSE30161 (39), GSE63885 (40) and GSE9891 (41), and 483 patients for the progression-free survival analysis using datasets GSE26193, GSE30161, GSE63885, GSE9891, GSE65986 (42) on Kaplan-Meier Plotter (43).

Cell lines and cell culture. Human ovarian cancer cells A2780 (cat. no. CL-0013; Procell Life Science \& Technology Co., Ltd.) were cultured in RPMI-1640 medium supplemented with $10 \%$ FBS and penicillin (100 IU/ml) and streptomycin (100 $\mu \mathrm{g} / \mathrm{ml})$ (all Gibco; Thermo Fisher Scientific, Inc.). HEY cells (gifted from Dr Jianjun Wei; Laboratory at Northwestern University) were cultured in DMEM (Gibco; Thermo Fisher Scientific, Inc.) supplemented with $10 \%$ FBS. All the cells were maintained in a humidified incubator at $37^{\circ} \mathrm{C}$ with $5 \% \mathrm{CO}_{2}$.

Immunohistochemistry (IHC). IHC staining of the tissue microarray (TMA) was performed on $4-\mu \mathrm{m}$ sections sliced from each TMA receiver block fixed with $4 \%$ paraformaldehyde at room temperature for $48 \mathrm{~h}$ and embedded in paraffin. Tissue slides were deparaffinized in xylene and rehydrated in a graded series of ethanol (10 min each in 100, 95, 80 and 70\% ethanol). Antigen retrieval was performed using a heat-induced epitope retrieval method with $10 \mathrm{mmol} / \mathrm{l}$ EDTA buffer ( $\mathrm{pH} 8.0$ ) at $98^{\circ} \mathrm{C}$ for $15 \mathrm{~min}$. Endogenous peroxidase activity was quenched with $3 \%$ hydrogen peroxide in methanol for $15 \mathrm{~min}$ at $37^{\circ} \mathrm{C}$, and non-specific binding was blocked by incubation with donkey serum as part of the SP9000 IHC kit (OriGene Technologies, Inc.; cat. no. SP9000) for $30 \mathrm{~min}$ at $37^{\circ} \mathrm{C}$. The slides were subsequently incubated overnight at $4^{\circ} \mathrm{C}$ in a humid chamber with anti-IQGAP3 (Abcam; cat. no. ab219354) antibody at a dilution of $3 \mu \mathrm{g} / \mathrm{ml}$. Staining was visualized using I-View 3,3'-diaminobenzidine staining detection system (OriGene Technologies, Inc.; cat. no. ZLI-9018). The IHC score was determined using a semi-quantitative method based on the extent and intensity of positively stained cells. The percentage of positive cells within each sample was scored independently from 0 to $100 \%$ upon observation under a light microscope (magnification, x10). The intensity of immunostaining was graded as follows: 0 , Negative; 1 , weak; 2, moderate; and 3, strong. The final IHC score was generated by multiplying the percentage extent with the staining intensity score. Then, two gynecological pathologists independently reviewed the IHC staining. High IQGAP3 expression grade was defined as a final IHC score $\geq 100$.

Stable and transient transfection. For stable transfection, lentiviral vector GV493 (hU6-MCS-CBh-gcGFP-IRES-puromycin) was packaged with IQGAP3 short hairpin (sh)RNA along with the respective negative control (NC), which were purchased from Shanghai GeneChem Co., Ltd. A total of $1 \times 10^{5}$ cells were plated into 6 -well plates $24 \mathrm{~h}$ prior to stable transfection. Multiplicity of infection (MOI) was determined and the lentivirus was added to the culture medium complemented with the transfection reagent HiTransGA (Shanghai 
GeneChem Co., Ltd.) with a MOI value of 20-50. After $24 \mathrm{~h}$ incubation, the medium was replaced with fresh culture medium containing $2 \mu \mathrm{g} / \mathrm{ml}$ puromycin (Sigma-Aldrich; Merck $\mathrm{KGaA}$ ) for selection of the stably transfected colonies.

Transient transfection was performed using small interfering (si)RNAs purchased from Shanghai GenePharma Co., Ltd. at a concentration of $20 \mu \mathrm{M}$. RNAi-mediated knockdown was performed with the following siRNAs: si-IQGAP3-1, 5'-GGCAGAAACUAGAAGCAUA-3'; si-IQGAP3-2, 5'-GAG CCAACCAGGACACUAA-3'; si-CDC42, 5'-GGACGGAUU GAUUCCACAU-3'; and si-NC, 5'-UUCUCCGAACGUGUC ACGUTT-3'. Cells were transfected with Lipofectamine ${ }^{\circledR} 2000$ (Invitrogen; Thermo Fisher Scientific, Inc.) according to the manufacturer's protocol. The subsequent experiments were performed 24-48 h after transfection.

$R N A$ extraction and reverse transcription-quantitative (RT- $q)$ $P C R$. Total RNA was extracted from tissue samples and cultured cells using TRIzol ${ }^{\circledR}$ reagent (Invitrogen; Thermo Fisher Scientific, Inc.) according to the manufacturer's protocol. mRNA was then reverse-transcribed into cDNA using PrimeScript cDNA Synthesis kit (Takara Bio, Inc.) at $37^{\circ} \mathrm{C}$ for $1 \mathrm{~h}$ and then at $85^{\circ} \mathrm{C}$ for 5 min according to the manufacturer's protocol. qPCR was performed using SYBR-Green Premix Ex Taq II (Takara Bio, Inc.) with a StepOne Plus RT PCR system (Applied Biosystems; Thermo Fisher Scientific, Inc.). The reaction conditions were as follows: Initial denaturation at $95^{\circ} \mathrm{C}$ for $5 \mathrm{sec}$, followed by 40 cycles of annealing at $60^{\circ} \mathrm{C}$ for $10 \mathrm{sec}$ and an extension at $72^{\circ} \mathrm{C}$ for $30 \mathrm{sec}$. $\beta$-actin was used as the endogenous control. The primers were designed based on the GeneBank sequences. The primer sequences used were: IQGAP3 forward, 5'-GTGCAGCGGATCAACAAAGC-3' and reverse, 5'-ACGATGCAACAGGGTACACTG-3'; and $\beta$-actin forward, 5'-GAGGCACTCTTCCAGCCTTC-3' and reverse, 5'-GGATGTCCACGTCACATTC-3'. The comparative threshold cycle method, $2^{-\Delta \Delta \mathrm{Cq}}$, was used to calculate the relative gene expression level (44).

Western blotting. Cells were harvested and lysed in RIPA lysis buffer (Beyotime Institute of Biotechnology) with PMSF (1\%) and $\mathrm{NaF}(1 \%)$. Protein samples were incubated for $30 \mathrm{~min}$ on ice and cell debris were removed by centrifugation at $12,000 \times \mathrm{g}$ at $4^{\circ} \mathrm{C}$ for $15 \mathrm{~min}$. The protein concentration was determined using a bicinchoninic acid assay kit (Thermo Fisher Scientific, Inc.). Protein samples $(30 \mu \mathrm{g})$ were separated by SDS-PAGE (5\% stacking gel and 10\% separating gel) and transferred to a PVDF membrane (EMD Millipore) using a Bio-Rad Trans-blot system (Bio-Rad Laboratories, Inc.). After blocking with 5\% skimmed milk for $1 \mathrm{~h}$ at room temperature, the membrane was incubated overnight at $4^{\circ} \mathrm{C}$ with the primary antibodies. The membranes were then rinsed with TBST ( $0.1 \%$ Tween-20) followed by incubation with a horseradish peroxidase-conjugated secondary antibody for $1 \mathrm{~h}$ at room temperature. Signals were detected using enhanced chemiluminescence (PerkinElmer, Inc.) with ImageQuant LAS 4000 (GE Healthcare Life Sciences). $\beta$-actin was used as the endogenous control. Densitometry analysis was performed using ImageJ version $1.52 \mathrm{~g}$ (National Institutes of Health).

The antibodies used were: Rabbit anti-human IQGAP3 (1:1,000; Abcam; cat. no. ab219354), rabbit anti-human
CDC42 (1:1,000; Affinity Biosciences; cat. no. DF6322), rabbit anti-human Zinc Finger E-Box Binding Homeobox 1 (ZEB-1; 1:1,000; CST Biological Reagents Co., Ltd.; cat. no. 3396), rabbit anti-human $\mathrm{N}$-cadherin (N-CAD; 1:1,000; CST Biological Reagents Co., Ltd.; cat. no. 13116), rabbit anti-human E-cadherin (E-CAD; 1:1,000; CST Biological Reagents Co., Ltd.; cat. no. 3195), rabbit anti-human Vimentin (1:1,000; CST Biological Reagents Co., Ltd.; cat. no. 5741), rabbit anti-human Snail (1:1,000; CST Biological Reagents Co., Ltd.; cat. no. 3879), rabbit anti phospho-(p-)AKT (1:1,000; Abcam; cat. no. ab66138), rabbit anti-human $A K T$ (1:1,000; Abcam; cat. no. ab179463), rabbit anti-human PI3K (1:1,000; Abcam; ab182651), rabbit anti-human phosphorylated (p-)mTOR (1:1,000; CST Biological Reagents Co., Ltd.; cat.no.2971), rabbit anti-human $m$ TOR (1:1,000; CST Biological Reagents Co., Ltd.; cat. no. 2983), rabbit anti-human $\mathrm{Bcl} 2$ (1:1,000; CST Biological Reagents Co., Ltd.; cat. no. 2876), rabbit anti-human caspase 3 (1:1,000; CST Biological Reagents Co., Ltd.; cat. no. 8G10), rabbit anti-human p-ATM Serine/Threonine Kinase (1:1,000; CST Biological Reagents Co., Ltd.; cat. no. 5883), rabbit anti-human ATM (1:1,000; CST Biological Reagents Co., Ltd.; cat. no. 2873), rabbit anti-human Checkpoint Kinase 2 (CHK2; 1:1,000; CST Biological Reagents Co., Ltd.; cat. no. 2662), rabbit anti-human RAD51 (1:10,000; Abcam; cat. no. ab133534) mouse anti-human $\operatorname{Bax}(1: 1,000$; CST Biological Reagents Co., Ltd.; cat. no. 2772), mouse anti-human caspase9 (1:1,000; CST Biological Reagents Co., Ltd.; cat. no. 9508), rabbit anti-human Pgp (1:1,000; Abcam; cat. no. ab103477) and mouse anti-human $\beta$-actin $(1: 1,000$; CST Biological Reagents Co., Ltd.; cat. no. 3700).

The secondary antibodies used were: Horseradish peroxidase-conjugated anti-rabbit (1:5,000; Sigma-Aldrich; Merck $\mathrm{KGaA}$; cat. no. A0545) or anti-mouse secondary antibody (1:5,000; Sigma-Aldrich; Merck KGaA; cat. no. A9044).

Cell proliferation assay. The proliferative ability of cells was measured using an MTT assay. Each cell line was seeded in quintuplicate into 96 -well plates $\left(0.8-1 \times 10^{3}\right.$ cells/well) for 0-4 days. At specified time points, $20 \mu \mathrm{l}$ MTT reagent (Sigma-Aldrich; Merck KGaA) at $5 \mathrm{mg} / \mathrm{ml}$ concentration was added to each well, and the cells were incubated for an additional $3.5 \mathrm{~h}$ at $37^{\circ} \mathrm{C}$. Subsequently, the supernatants were discarded and $100 \mu \mathrm{l}$ DMSO (Sigma-Aldrich; Merck KGaA) was added to each well. The absorbance at $490 \mathrm{~nm}$ was measured using a Varioskan Flash microplate reader (Thermo Fisher Scientific, Inc.).

Cell migration and invasion assay. Cell migration and invasion were analyzed using Boyden chamber-style cell culture inserts, with and without Matrigel (BD Biosciences), respectively. Matrigel was thawed at $4^{\circ} \mathrm{C}$ and then coated onto the Transwell inserts, after which the gel was allowed to set at $37^{\circ} \mathrm{C}$ for $1 \mathrm{~h}$. Ovarian cancer cells $\left(2 \times 10^{5}\right.$ cells $)$ were seeded in the upper chamber of the Transwell inserts (24-well plate; 8- $\mu \mathrm{m}$ pore size; BD Biosciences) with $200 \mu \mathrm{l}$ serum-free media. The lower chambers were filled with $700 \mu \mathrm{l}$ culture media containing $10 \%$ FBS as the chemoattractant. After 6-48 h of incubation, the cells on the lower surface of the membrane were washed with PBS and fixed in $100 \%$ methanol for $15 \mathrm{~min}$ at room temperature. Then, cells were stained with 
$0.1 \%$ crystal violet for $20 \mathrm{~min}$ at room temperature to quantify migration and invasion. Transwell inserts were observed under a light microscope (magnification, x10) and cells in 10 random fields were counted.

Clonogenic assay. For the colony formation assay, 500 cells were seeded into each well of a 6-well plate and maintained in media containing $10 \% \mathrm{FBS}$ at optimum conditions of $37^{\circ} \mathrm{C}$ with $5 \% \mathrm{CO}_{2}$ for 10-14 days, until the colonies became visible to the naked eye. Colonies were then fixed with $100 \%$ methanol at room temperature for $15 \mathrm{~min}$ and stained with $0.1 \%$ crystal violet at room temperature. Colonies with $>50$ cells were counted manually under a light microscope (magnification, x10) for quantification.

Apoptosis assay. Apoptosis was detected using an Annexin V-FITC and propidium iodide (PI) kit (BD Biosciences), according to the manufacturer's protocol. A2780 and HEY cells were transfected with $20 \mu \mathrm{M}$ si-IQGAP3 or si-NC, and were harvested $48 \mathrm{~h}$ after transfection with EDTA-free trypsin, centrifuged at $800 \mathrm{x}$ g for $5 \mathrm{~min}$ at room temperature, washed twice with cold PBS, resuspended at a concentration of $1 \times 10^{6}$ cells $/ \mathrm{ml}$ and mixed with $100 \mu 11 \mathrm{X}$ binding buffer. Subsequently, cells were stained with $5 \mu$ l Annexin V-FITC and $5 \mu \mathrm{l} \mathrm{PI}$ at room temperature for $15 \mathrm{~min}$ in the dark, after which $300 \mu 1 \mathrm{X}$ binding buffer was added and the cells were analyzed by flow cytometry (FACSCalibur; BD Biosciences) within $1 \mathrm{~h}$. The results were analyzed using FlowJo software version X.0.7 (FlowJo, LLC).

Cell viability assay. A total of $2 \times 10^{3}$ cells/well were seeded in 96-well plates. The A2780 and HEY cells were exposed to olaparib (Selleck Chemicals; cat. no. AZD2281) at various final concentrations $(0,5,10,20,40$ and $80 \mu \mathrm{mol} / \mathrm{ml})$ at $37^{\circ} \mathrm{C}$ for $36-72 \mathrm{~h}$. Each concentration was repeated in quintuplicate wells. Subsequently, $20 \mu \mathrm{l} 5 \mathrm{mg} / \mathrm{ml}$ MTT was added to each well. After incubation for $3.5 \mathrm{~h}$, the medium was replaced with $100 \mu \mathrm{l}$ DMSO, and cell viability was determined by analyzing the absorbance values at $490 \mathrm{~nm}$ on a Varioskan Flash microplate reader (Thermo Fisher Scientific, Inc.).

Mouse xenograft models. HEY cells that were stably transfected with IQGAP3-shRNA and the corresponding NC were used for the in vivo experiments. For in vivo experiments, eight female athymic BALB-c nude mice (age, 5 weeks; weight, 20-30 g) were purchased from Nanjing Biochemical Research Institute and housed in a standard pathogen-free condition in individually ventilated cages with HEPA filters at the ambient temperature of $30-31^{\circ} \mathrm{C}$ and humidity of $50-60 \%$ with $12 \mathrm{~h}$ light/dark cycle, and adequate access to food and water. For tumor formation assays, $1 \times 10^{7}$ cells (knockdown or control), resuspended in $200 \mu \mathrm{l}$ PBS were subcutaneously injected into either side of the axilla.

For metastasis assays, $1 \times 10^{7}$ cells were intraperitoneally injected individually in the experimental and control groups. After 2-3 weeks, bioluminescence images were captured on an In-vivo imaging system (Kodak 2000 Imager). The mice were euthanized via intraperitoneal injection of $200 \mathrm{mg} / \mathrm{kg}$ sodium phenobarbital and the tumors were excised, fixed with $4 \%$ paraformaldehyde at room temperature for $48 \mathrm{~h}$, paraffin-embedded and sectioned into 5- $\mu \mathrm{m}$ slices for hematoxylin and eosin staining. The tissue slides were stained with hematoxylin for $5 \mathrm{~min}$ and eosin for $10 \mathrm{~min}$ at room temperature and observed under a light microscope (magnification, $\mathrm{x} 4$ ).

Statistical analysis. GraphPad Prism version 7 (GraphPad Software, Inc.) was used to analyze data. A $\chi^{2}$ test was used to analyze the differences in clinical characteristics. Survival analysis was performed using Kaplan-Meier analysis and a log-rank test. An unpaired Student's t-test and a one-way ANOVA were used to determine the statistically significant differences between different groups. Fisher's least significant difference was used for the post-hoc test following ANOVA. Data are presented as the mean \pm standard deviation of $\geq 3$ independent experiments. $\mathrm{P}<0.05$ was considered to indicate a statistically significant difference.

\section{Results}

IQGAP3 expression is upregulated in HGSOC. The mRNA and protein expression levels of IQGAP3 in healthy fallopian tube and HGSOC tissues were determined using RT-qPCR and western blotting, respectively. The mRNA expression level of IQGAP3 was significantly higher in HGSOC tissues compared with the control samples (Fig. 1D). Furthermore, $I Q G A P 3$ protein expression was significantly upregulated in HGSOC tissues compared with the fallopian tubal samples (Fig. 1C).

Upregulated expression of IQGAP3 is associated with a less favorable prognosis. To examine whether upregulated expression of IQGAP3 was associated with clinical prognosis, IHC staining was performed on 149 HGSOC samples (Fig. 1E). Most positive staining was observed in the cytoplasm and at the cell membrane. Moreover, a high expression of IQGAP3 was observed in $53.02 \%$ (79/149) of tissues. Subsequently, the relationship between IQGAP3 and clinicopathological characteristics were assessed (Table I). The patients with a lower expression of IQGAP3 had longer survival times compared with those with higher IQGAP3 expression levels. A log-rank test demonstrated that the upregulated expression of IQGAP3 was significantly associated with overall survival $(\mathrm{P}=0.0149)$, as well as progression-free survival ( $\mathrm{P}=0.0044$; Fig. 1A).

Survival analysis performed on GEO cohorts using Kaplan-Meier Plotter, showed a significant association between IQGAP3 expression and both overall and progression-free survival (Fig. 1B). In addition, further analysis indicated that the expression of IQGAP3 was associated with several other clinicopathological parameters, including recurrence of the disease $(\mathrm{P}=0.0065)$, CA125 levels $(\mathrm{P}=0.0147)$ and peritoneal metastasis $(\mathrm{P}=0.0007$; Table $\mathrm{I})$.

Downregulation of IQGAP3 reduces proliferation and colony formation of HGSOC ovarian cancer cells, and attenuates tumorigenicity in a xenograft model. Downregulation of $I Q G A P 3$ resulted in the reduced proliferation of ovarian cancer cells in vitro. Moreover, two siRNAs, si-IQGAP3-1 and si-IQGAP3-2, were used to silence IQGAP3 in A2780 and HEY cells. MTT assays results identified a significant suppression of the proliferative capacity in the two cell lines 
A

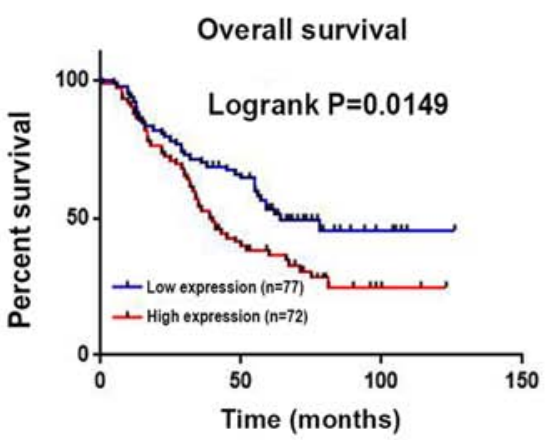

B

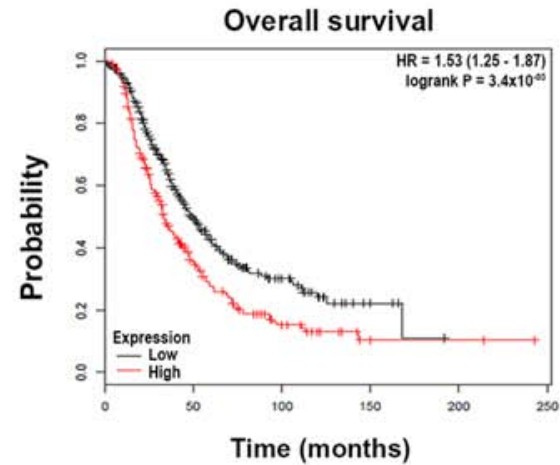

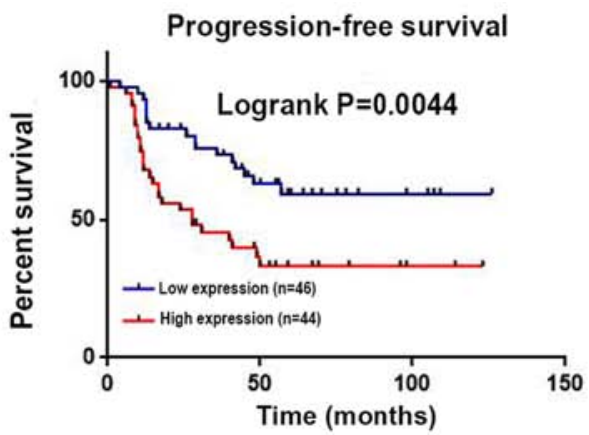

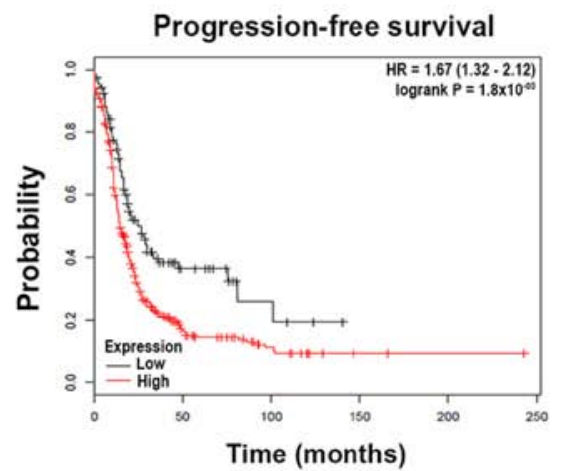

C

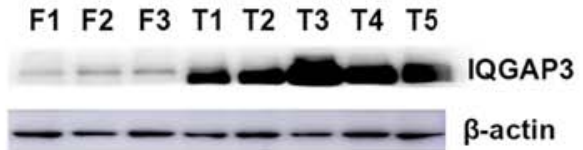

E

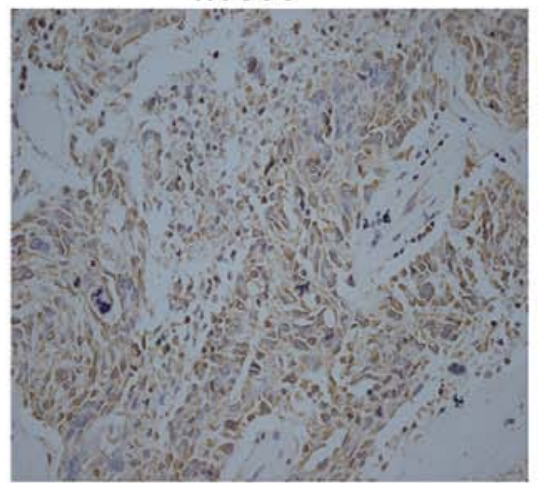

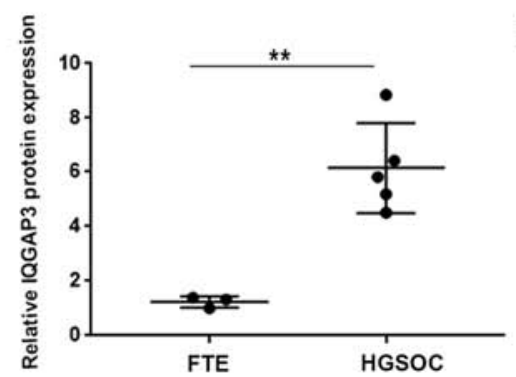

D

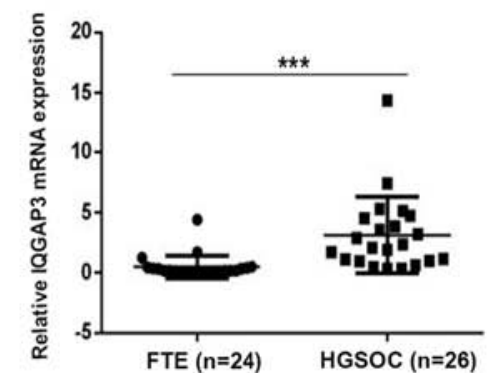

FTE

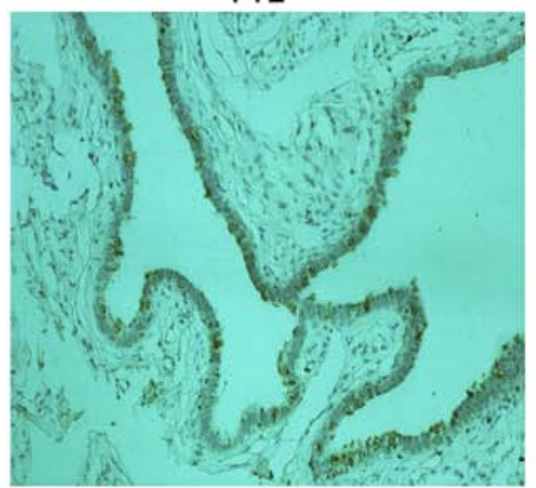

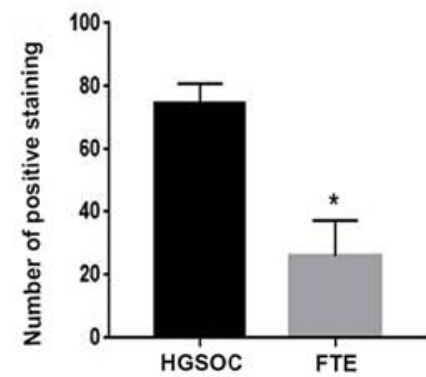

Figure 1. IQGAP3 expression is upregulated in HGSOC and its increased expression is associated with a poorer prognosis. (A) Survival analysis based on immunohistochemical analysis identified significantly improved overall survival (log rank $\mathrm{P}=0.0149)$ and progression-free survival $(\log$ rank $\mathrm{P}=0.0044)$ in patients with lower expression levels of IQGAP3. (B) Kaplan-Meier survival plots based on data obtained from the Gene Expression Omnibus database had improved overall and progression-free survival in cases with lower expression levels of IQGAP3. (C) Western blotting results demonstrated higher protein expression levels of IQGAP3 in HGSOC tissues (T1-T5) compared with healthy FTE (F1-F3). Expression of IQGAP3 between the two groups was significantly different. (D) Reverse transcription-quantitative-PCR analysis indicated higher mRNA expression levels of IQGAP3 in HGSOC tissues (n=26) compared with FTE (n=24). (E) Immunohistochemical staining of IQGAP3 in HGSOC and FTE samples. Magnification, $\mathrm{x} 40 .{ }^{*} \mathrm{P}<0.05{ }^{* * *} \mathrm{P}<0.01 ;{ }^{* * * *} \mathrm{P}<0.001$. IQGAP3, IQ motif containing GTPase Activating Protein 3; HGSOC, high-grade serous ovarian cancer; FTE, fallopian tube epithelium.

following transfection with the siRNAs compared with the NCs (Fig. 2A).

These findings were further assessed in the in vivo experiments, where xenografts of BALB-c nude mice were established with injection of HEY cells stably transfected with sh-IQGAP3 or NC (Fig. 2C). After 3 weeks, the mice were euthanized, imaged on a bioluminescence imaging system, and the tumors were excised and weighed. It was found that 
Table I. Association between IQGAP3 expression and clinicopathologic characteristics.

\begin{tabular}{lccc}
\hline $\begin{array}{l}\text { Clinicopathologic } \\
\text { characteristics }\end{array}$ & $\begin{array}{c}\text { High } \\
\text { expression }\end{array}$ & $\begin{array}{c}\text { Low } \\
\text { expression }\end{array}$ & P-value \\
\hline $\begin{array}{l}\text { Age, years } \\
<55\end{array}$ & 42 & 30 & 0.2089 \\
$\quad 555$ & 37 & 40 & \\
FIGO stage & & & 0.4367 \\
I + II & 21 & 15 & \\
III + IV & 57 & 55 & \\
CA125, U/ml & & & $0.0147^{\mathrm{a}}$ \\
$<600$ & 20 & 38 & \\
$\geq 600$ & 50 & 41 & \\
Ascites, ml & & & 0.3255 \\
Yes & 59 & 58 & \\
No & 13 & 19 & \\
Peritoneal metastasis & & & $0.0007^{\mathrm{b}}$ \\
Yes & 33 & 20 & \\
No & 32 & 64 & \\
Lymph node metastasis & & & 0.1703 \\
Positive & 12 & 10 & \\
Negative & 23 & 38 & \\
Recurrence & & & $0.0065^{\mathrm{b}}$ \\
Yes & 56 & 41 & \\
No & 8 & 20 & \\
\hline
\end{tabular}

${ }^{\mathrm{a}} \mathrm{P}<0.05$; ${ }^{\mathrm{b}} \mathrm{P}<0.001$. FIGO, International Federation of Gynecology and Obstetrics; CA125, cancer antigen 125.

there was a significant decrease in tumor size and tumor weight in the sh-IQGAP3 group compared with the NC group (Fig. 2D and E), supporting the in vitro results. Therefore, the results demonstrated the contribution of IQGAP3 to tumor proliferation.

Knockdown of IQGAP3 also significantly reduced colony formation in both A2780 and HEY cell lines (Fig. 2B).

IQGAP3 increases migration and invasion of ovarian cancer cells via epithelial-to-mesenchymal transition (EMT). Transwell assays were used to examine the role of IQGAP3 on migration and invasion in vitro. A2780 and HEY cells both had significantly decreased migratory and invasive capacities when IQGAP3 was knocked down compared with the respective NC (Fig. 3A and B).

Furthermore, the underlying mechanism contributing to this increase in tumorigenic features was determined by analyzing EMT-related factors. Knockdown of IQGAP3 had an effect on the expression of several EMT markers (Fig. 4). Silencing of IQGAP3 resulted in downregulation of mesenchymal markers, including ZEB-1, Vimentin, N-CAD and Snail, while the expression of the epithelial marker E-CAD was upregulated. Thus, it was suggested that IQGAP3 induced the migration and invasion of ovarian cancer cells via induction of EMT.
IQGAP3 reduces tumor metastasis in vivo. To evaluate the role of IQGAP3 on metastasis of ovarian cancer in vivo, female nude mice were injected intraperitoneally with sh-IQGAP3-HEY cells or their corresponding NCs. Then, 3 weeks after injection, the mice were euthanized and the peritoneal cavities were examined for metastases. Consistent with the in vitro experimental results, mice injected with IQGAP3-silenced cells exhibited significantly lower numbers of metastatic nodules compared with the respective NC group $(\mathrm{P}<0.05$; Fig. 3C). Bioluminescence imaging also identified larger metastatic foci in the control group compared with the knockdown group (Fig. 2E).

The excised metastatic nodules were fixed with formalin and paraffin embedded and $4-\mu \mathrm{m}$ thick slices were sectioned. Subsequently, the slides were stained using hematoxylin and eosin staining (Fig. S1).

IQGAP3 knockdown promotes apoptosis in ovarian cancer cells. To assess the effects of IQGAP3 knockdown on apoptosis of ovarian cancer cells, Annexin V-FITC/PI dual staining was performed following transfection with si-IQGAP3 or NC. Both A2780 and HEY cells exhibited significantly increased apoptosis following knockdown of IQGAP3 compared with the respective NC group (Fig. 5A and B). These results were further validated by the increased expression of the pro-apoptotic proteins Bax, Caspase 3 and Caspase 9, and decreased expression of $\mathrm{Bcl}-2$ following IQGAP3 knockdown (Fig. 4).

IQGAP3 knockdown increases sensitivity to chemotherapy with PARPi. The si-IQGAP3 transfected A2780 and HEY cells were exposed to various concentrations of olaparib $(5,10,20,40$ or $80 \mu \mathrm{mol} / \mathrm{ml})$ for $36-72 \mathrm{~h}$, after which, the cell viability was assessed using an MTT assay. Cells transfected with si-IQGAP3 exhibited increased sensitivity to olaparib compared with the respective control group (Fig. 6A). Western blotting results identified the downregulation of the expression levels of Rad51, p-ATM (normalized to total ATM) and CHK2 when IQGAP3 expression was knocked down (Fig. 4). Thus, knockdown of IQGAP3 may have sensitized cells to olaparib by downregulating key factors involved in the DNA damage response.

Phosphoglycolate Phosphatase ( $P g p)$ is a multidrug resistance protein that is localized in the cell membrane and is responsible for extruding several xenobiotics (including chemotherapeutic agents) outside the cells, rendering the cells chemoresistant (45). IQGAP3 knockdown reduced the expression of $P g p$, which in turn attenuated chemoresistance (Fig. 4). Therefore, it was speculated that this effect may underlie the enhanced sensitivity of cells towards olaparib following IQGAP3 knockdown.

IQGAP3 exerts its function via the regulation of CDC42. It has been reported that IQGAP3 is an effector of $C D C 42$ (28). $\mathrm{Xu}$ et al (35) also revealed that IQGAP3 may exert its oncogenic function in pancreatic cancer via the regulation of $C D C 42$. To determine whether IQGAP3 was associated with $C D C 42$ in ovarian cancer, the protein expression levels of $C D C 42$ in ovarian cancer cells were assessed by knocking down IQGAP3 expression. It was identified that knockdown of IQGAP3 decreased the expression of CDC42 (Fig. 4). 
A

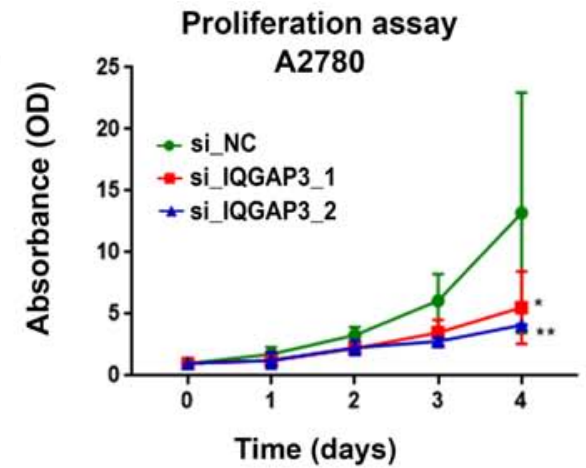

B

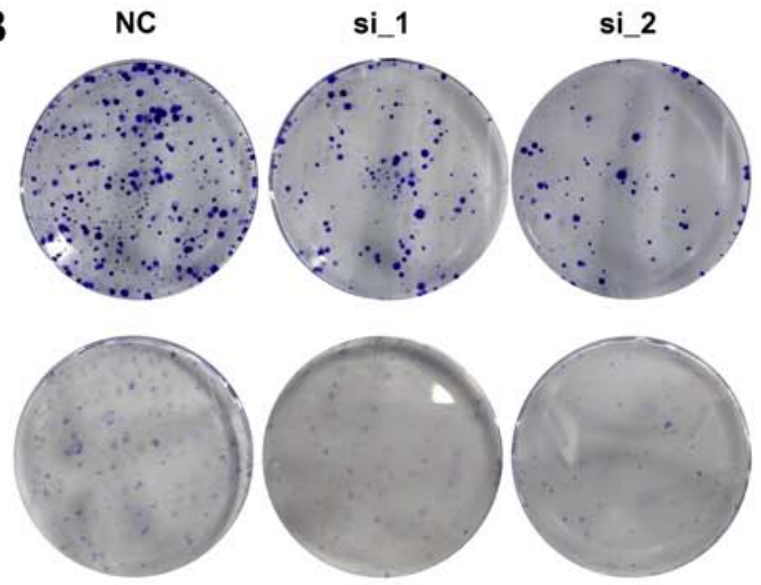

C

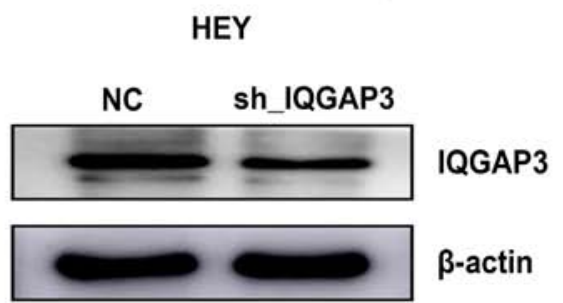

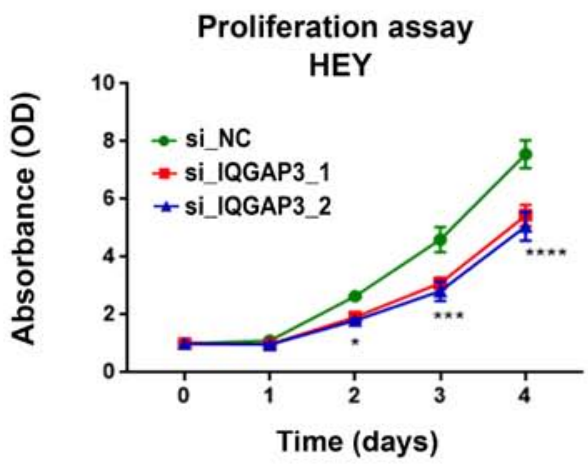
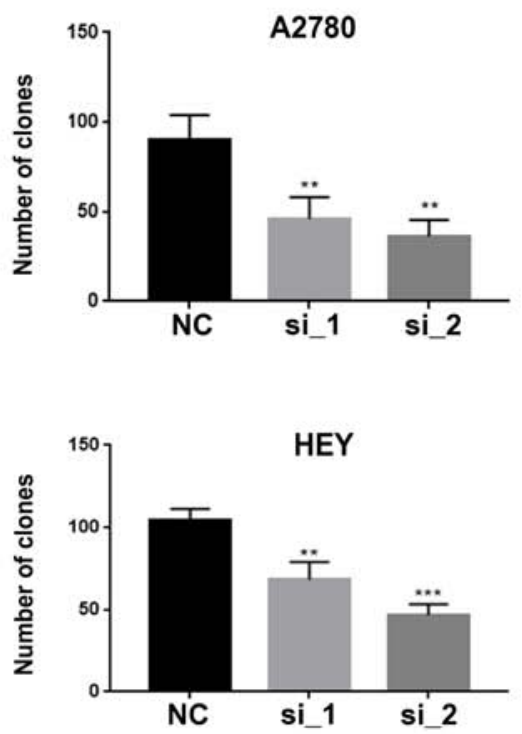

D

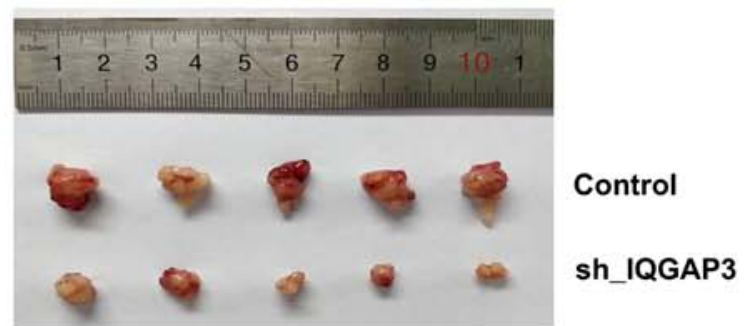

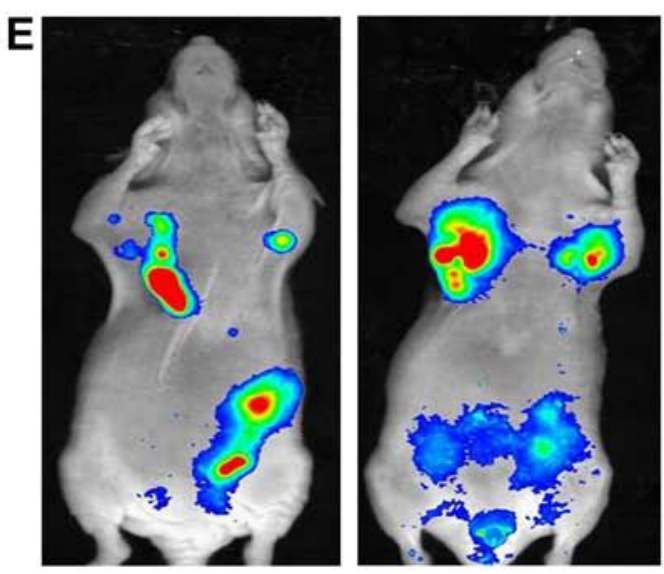
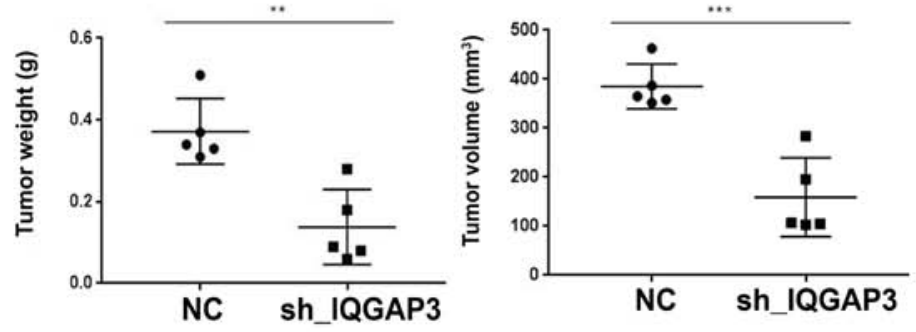

Figure 2. IQGAP3 promotes the proliferation of HGSOC in vitro and in vivo. (A) MTT assay identified significantly reduced proliferation in A2780 and HEY cells following knockdown of IQGAP3 using si-IQGAP3-1 and si-IQGAP3-2 compared with the corresponding control. (B) Silencing IQGAP3 reduced colony formation in A2780 and HEY cells compared with the respective controls. (C) Knockdown of IQGAP3 with sh-IQGAP3 in HEY cell line. (D) Knockdown of IQGAP3 resulted in reduced tumor forming capacity in nude xenograft mice compared with the corresponding controls. Control cells were injected in the right armpit and sh-IQGAP3-transfected cells were injected in the left armpit. The weight and the volume of the xenograft tumors were significantly different between the control group and the sh-IQGAP3-transfected group. (E) Bioluminescence imaging identified the effects of IQGAP3 silencing on tumor formation, as well as metastasis in vivo. Control cells were injected in the left armpit and IQGAP3 knockdown cells were injected in the right. Metastatic foci were more visible in the nude mice injected intraperitoneally with control (left) compared with sh-IQGAP3-transfected cells (right). ${ }^{*} \mathrm{P}<0.05 ;{ }^{* *} \mathrm{P}<0.01 ;{ }^{* * *} \mathrm{P}<0.001$; ${ }^{* * * * *} \mathrm{P}<0.0001$ vs. NC. IQGAP3, IQ motif containing GTPase Activating Protein 3; siRNA, small interfering; shRNA, short hairpin RNA; NC, negative control; shRNA, short hairpin RNA. 
A

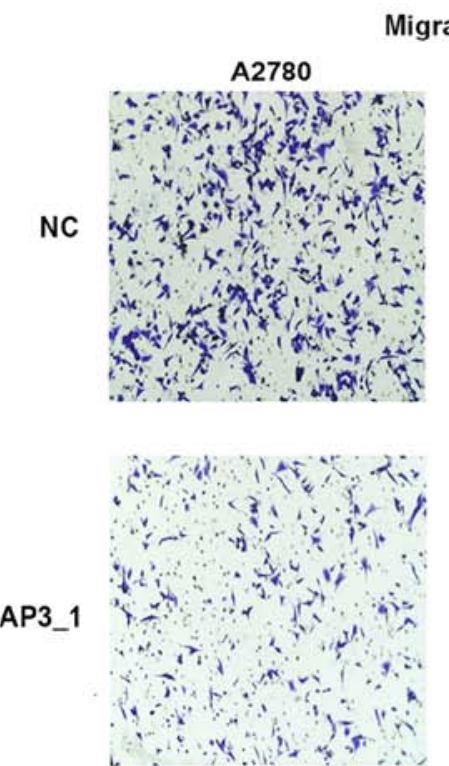

si_IQGAP3_1
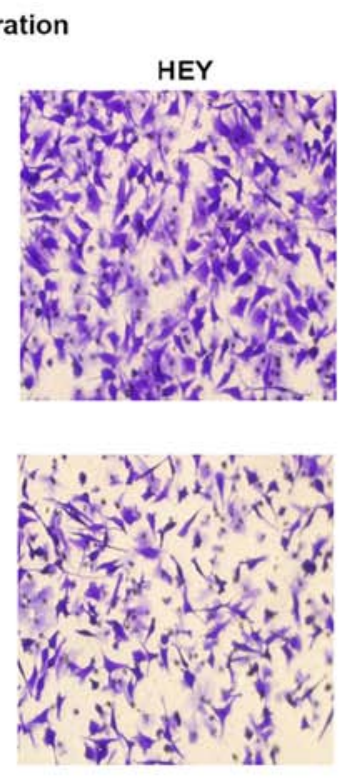

si_IQGAP3_2
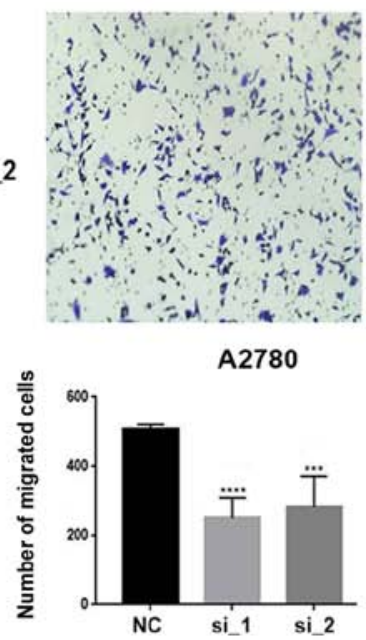

C
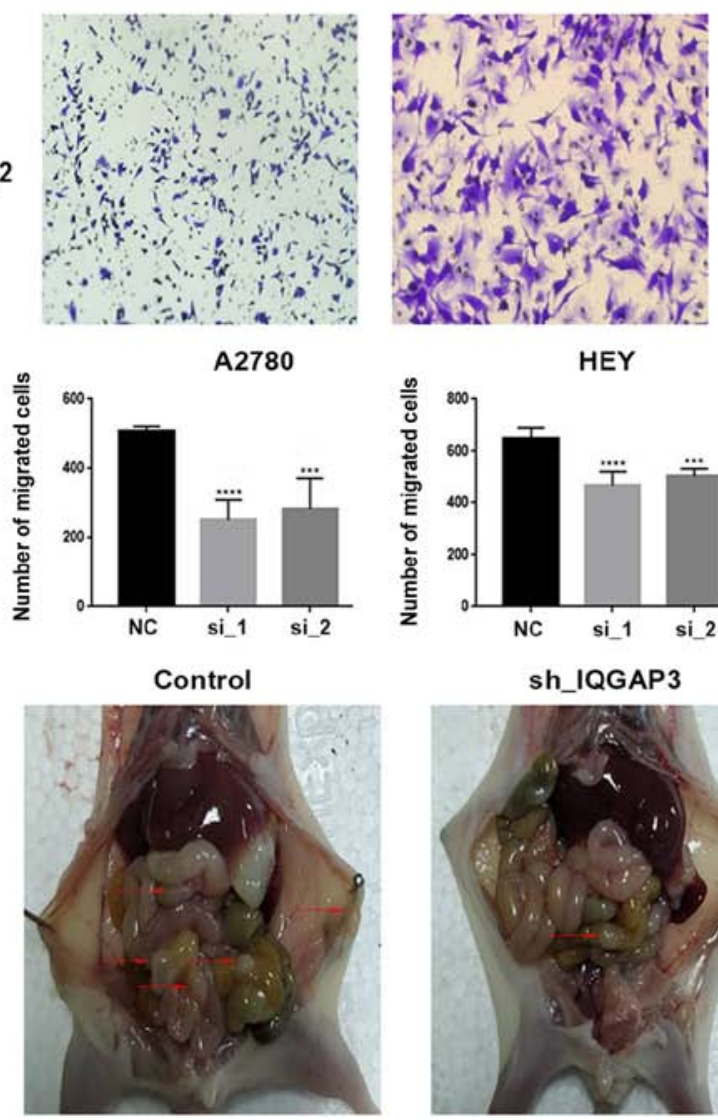

HEY

sh_IQGAP3
B
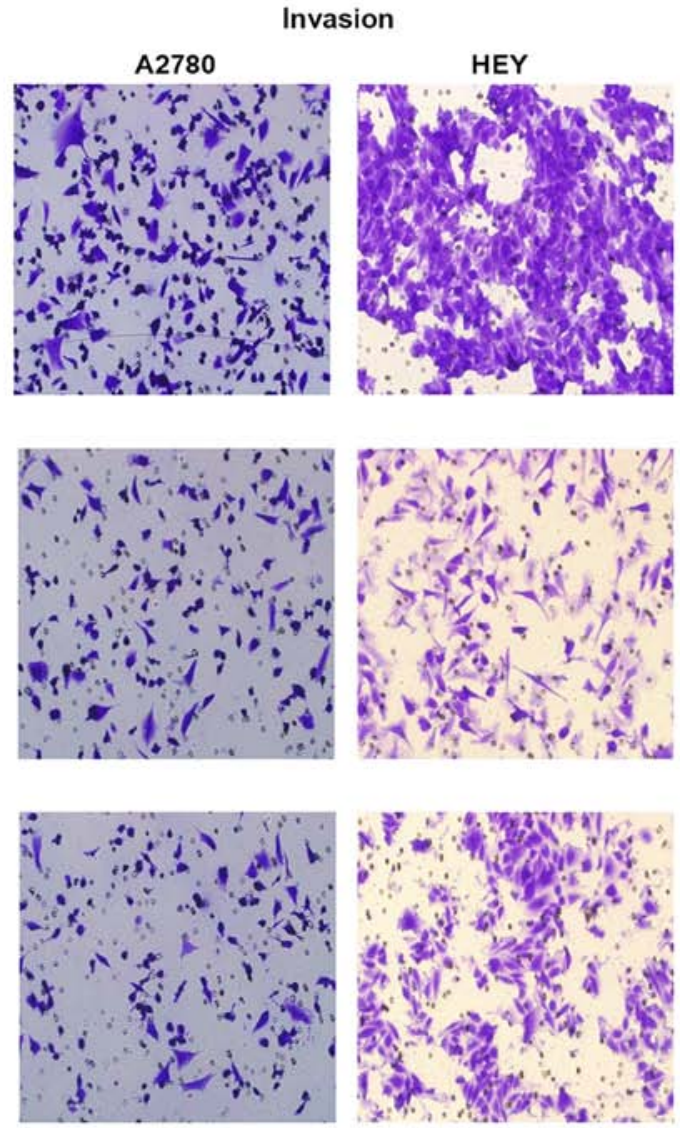

A2780
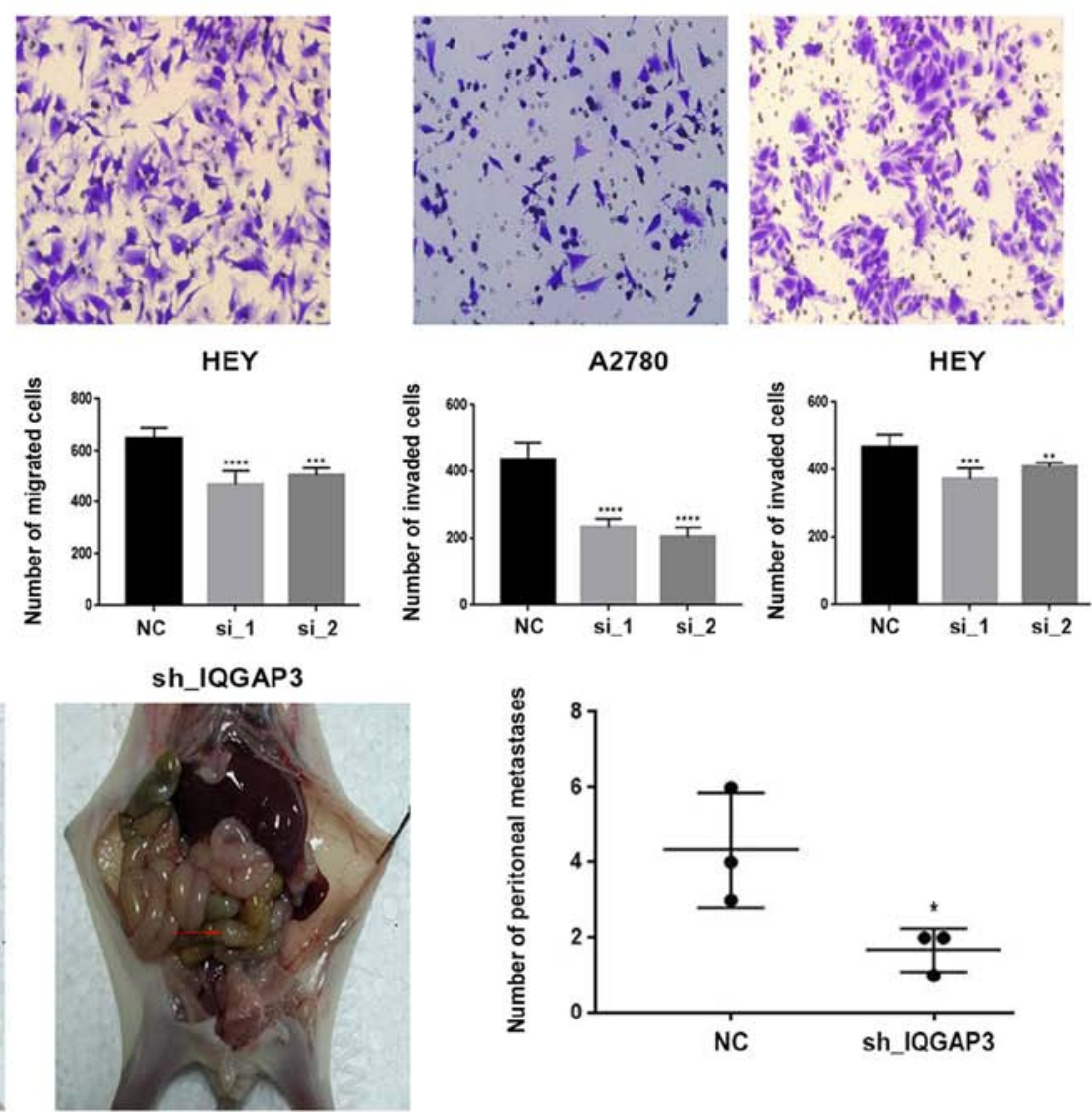

Figure 3. IQGAP3 potentiates the migratory and invasive capacities of the ovarian cancer cells in vitro and in vivo. Knockdown of IQGAP3 using two siRNAs significantly decreased the (A) migration and (B) invasion of A2780 and HEY cells. Quantitative analysis of migration and invasion. Magnification, x10. (C) In vivo experiments demonstrated significantly lower numbers of metastatic foci (arrows) in the nude mice injected with sh-IQGAP3-transfected cells compared with the control. ${ }^{*} \mathrm{P}<0.05 ;{ }^{* *} \mathrm{P}<0.01 ;{ }^{* * * *} \mathrm{P}<0.001 ;{ }^{* * * * *} \mathrm{P}<0.0001$ vs. NC. IQGAP3, IQ motif containing GTPase Activating Protein 3; shRNA, short hairpin RNA; NC, negative control; si, small interfering RNA.

Therefore, the effects of $C D C 42$ on the cancer cells were assessed. Knockdown of $C D C 42$ expression (Fig. 6B) resulted in a significant decrease in the proliferative potential of HEY cells (Fig. 6C). Furthermore, migration and invasion were inhibited, while apoptosis was enhanced following $C D C 42$ knockdown (Fig. 6D and E). Collectively, these results suggest that IQGAP3 may exert its effects via the regulation of $C D C 42$.

\section{Discussion}

The principle dilemma when dealing with ovarian cancer is the rate of distant metastasis at the time of diagnosis and its resistance to chemotherapy, which frequently results in negative consequences $(1,46-48)$. Thus, there is an unmet need for an improved understanding of the molecular mechanisms 

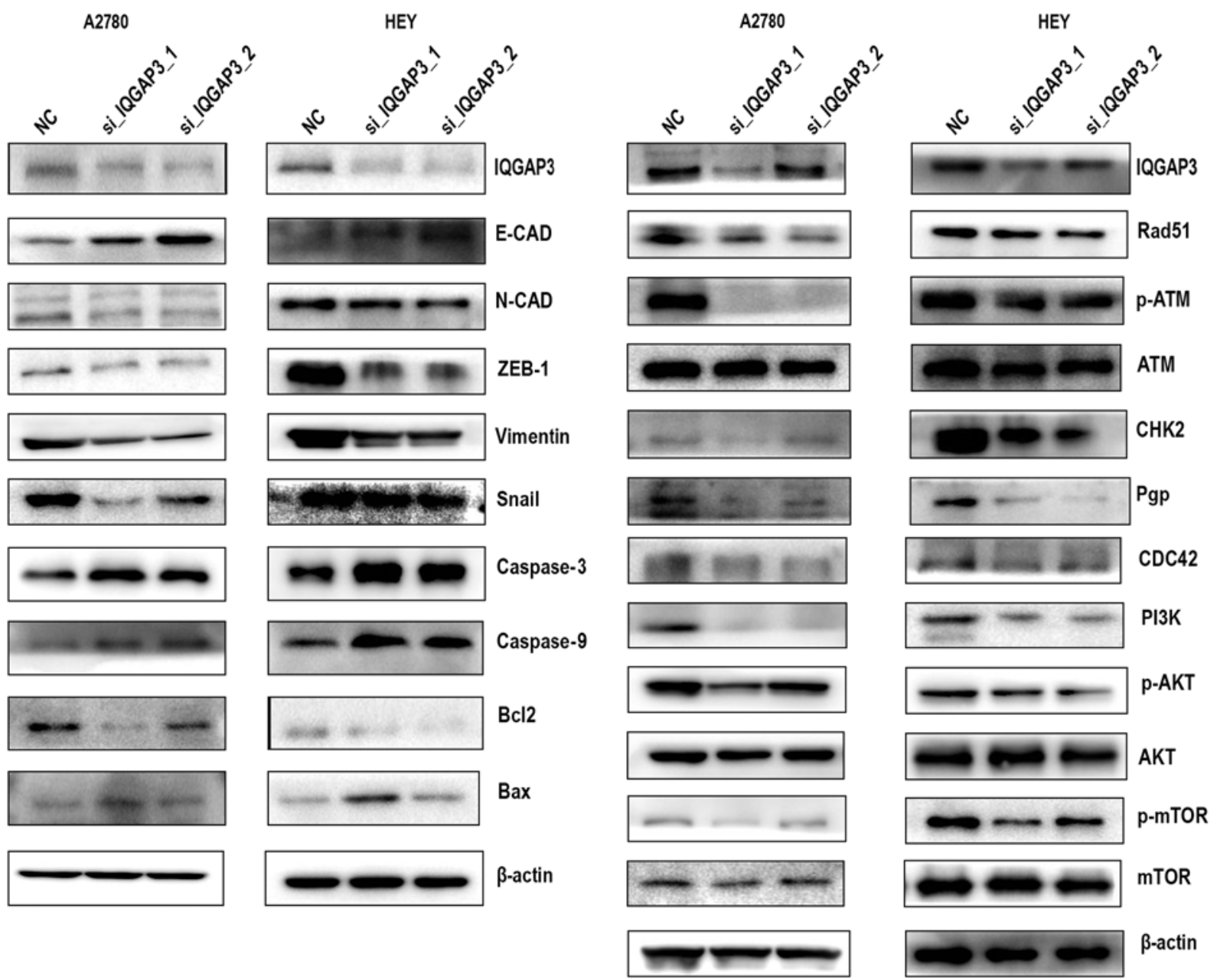

Figure 4. Western blot analysis revealed the changes in protein expression of several proteins following IQGAP3 knockdown using two siRNAs. Both A2780 and HEY cells had an altered protein expression following the knockdown. The alteration in the protein expression included EMT-related proteins (E-CAD, N-CAD, ZEB-1, Vimentin and Snail), apoptosis-related proteins (Caspase-3, Caspase-9, Bcl2 and Bax), proteins associated with DNA damage and chemoresistance (Rad51, p-ATM, ATM, CHK2 and Pgp), and proteins involved in the regulation and mechanism of the effect of IQGAP3 (CDC42, PI3K, p-AKT, AKT, p-mTOR and $m T O R$ ). $\beta$-actin was used as the internal control. IQGAP3, IQ motif containing GTPase Activating Protein 3; EMT, epithelial-to-mesenchymal transition; p-, phosphorylated; E-CAD, E-cadherin; N-CAD, N-cadherin; Pgp, phosphoglycolate phosphatase; Rad51, RAD51 recombinase; CHK2, checkpoint kinase 2; NC, negative control; si, small interfering RNA; ZEB-1, zinc finger E-Box binding homeobox 1.

involved in the proliferation, metastasis and chemoresistance of ovarian cancer.

Out of the three primary members of the IQGAP family, $I Q G A P 1$ has been reported to be an oncogene, and IQGAP2 a tumor suppressor $(24-26,49)$. Furthermore, IQGAP3 is a scaffolding protein, which interacts with various structural proteins that influence the cytoskeletal dynamics and intracellular signaling (28). IQGAP3 has also previously been implicated in the proliferation of epithelial cells (27). Moreover, previous studies have revealed the role of IQGAP3 in the proliferation and metastasis of lung, gastric, breast, pancreatic cancer, and colorectal cancer as well as hepatocellular carcinoma (29-35). Therefore, the role of IQGAP3 is crucial in the malignant transformation of several types of cancer. Yang et al (29) also reported that IQGAP3 promotes the metastasis of lung cancer cells by activating the epidermal growth factor receptor/ERK signaling pathway. In addition, Yang et al (29) used bioinformatics analysis to show that $I Q G A P 3$ is upregulated in several malignancies, including ovarian cancer. Furthermore, Wu et al (50) reported there were alterations in the genes regulating cytoskeleton remodeling in metastatic lung adenocarcinoma and that IQGAP3 was a marker of a less favorable prognosis.

The present results indicated that IQGAP3 was upregulated in ovarian cancer, and this enhanced expression resulted in increased proliferative and metastatic capacities in vitro and in vivo. Upon silencing IQGAP3, the aggressive nature of ovarian cancer cells was significantly abrogated. Thus, IQGAP3 may be a putative oncogene in HGSOC. Moreover, the upregulated expression of IQGAP3 was associated with a shorter overall and progression-free survival, cancer recurrence and CA125 expression. Kaplan-Meier survival analysis on data obtained from the online GEO database also demonstrated that patients with an upregulated expression of $I Q G A P 3$ exhibited reduced survival rates, further validating the in vitro and in vivo results. However, whether IQGAP3 is an independent poor prognostic factor of HGSOC is yet to be determined.

A number of in vitro and in vivo experiments were designed to establish the oncogenic potential of IQGAP3 in HGSOC. IQGAP3 expression was significantly upregulated in HGSOC compared with the healthy control. Cell proliferation 
A

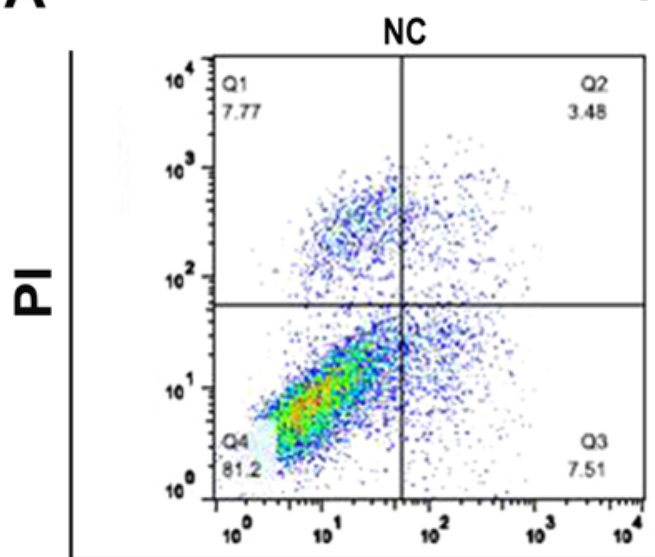

A2780

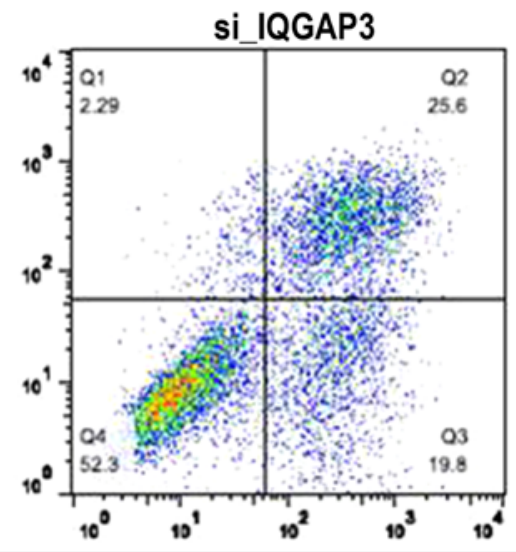

Annexin V-FITC

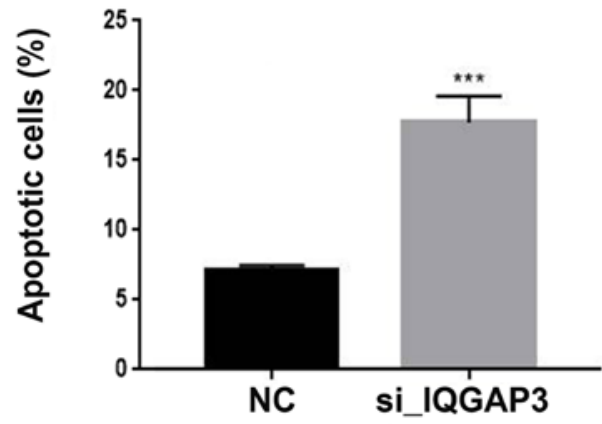

Early apoptosis

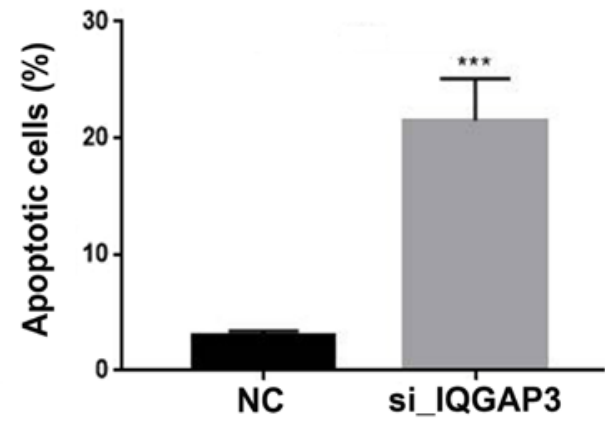

Late apoptosis
B

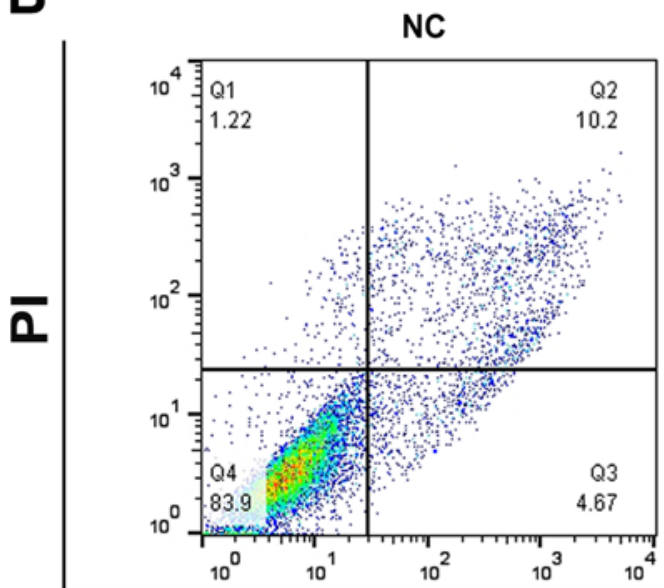

HEY

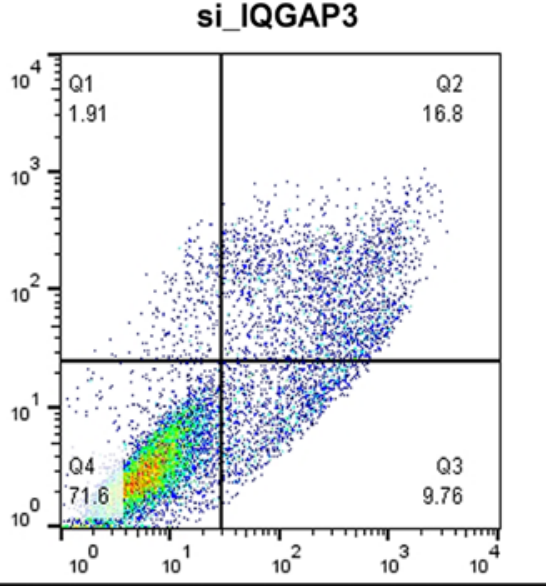

Annexin V-FITC

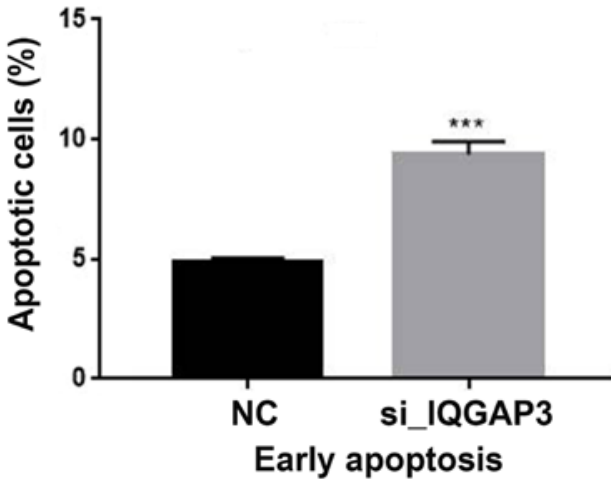

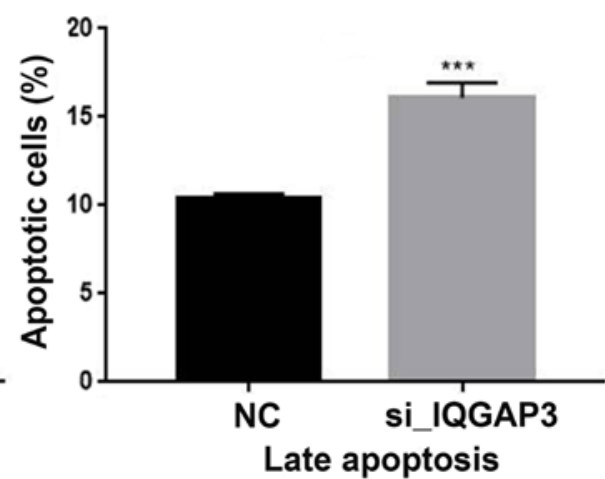

Figure 5. IQGAP3 increases apoptotic potential in cancer cell lines. Flow cytometry analysis indicated increased early, as well as late apoptosis in (A) A2780 and (B) HEY cells following knockdown of IQGAP3. ${ }^{* * *} \mathrm{P}<0.001$ vs. NC. IQGAP3, IQ motif containing GTPase Activating Protein 3; NC, negative control; si, small interfering RNA; PI, propidium iodide. 
A

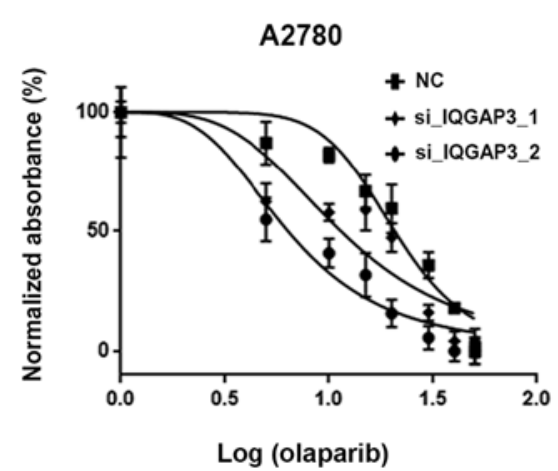

D

Migration

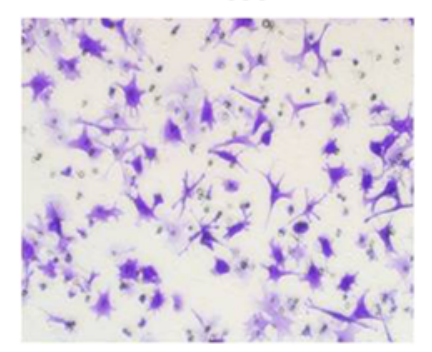

Invasion

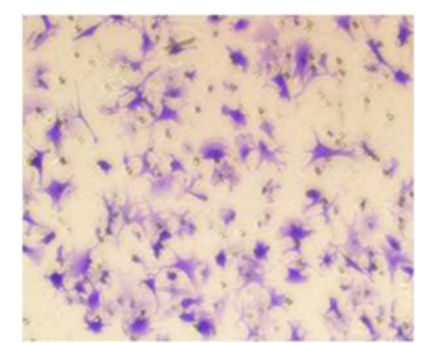

E

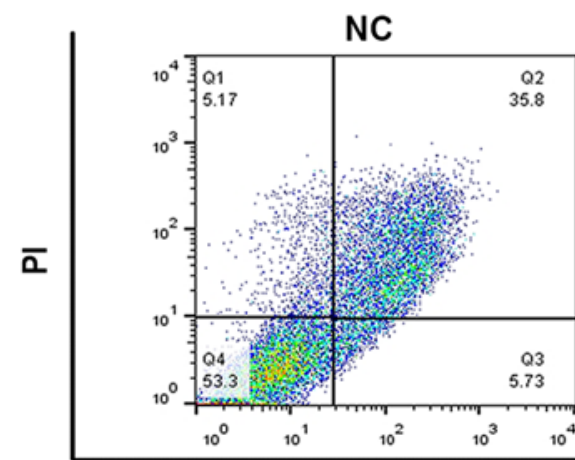

HEY

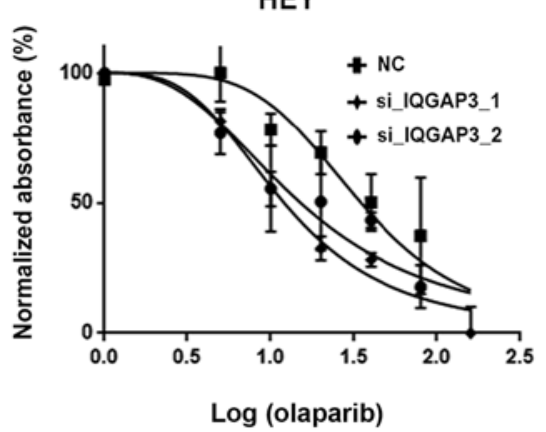

si_CDC42
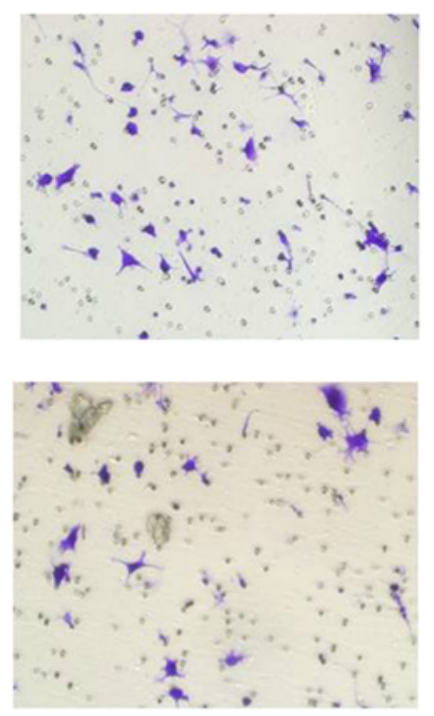

si_CDC42

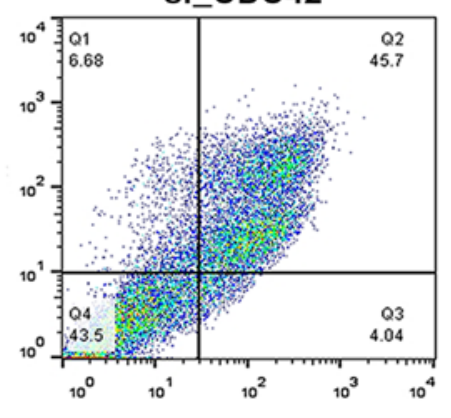

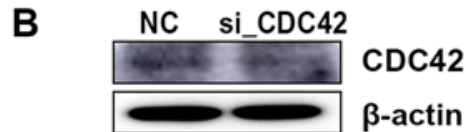

C
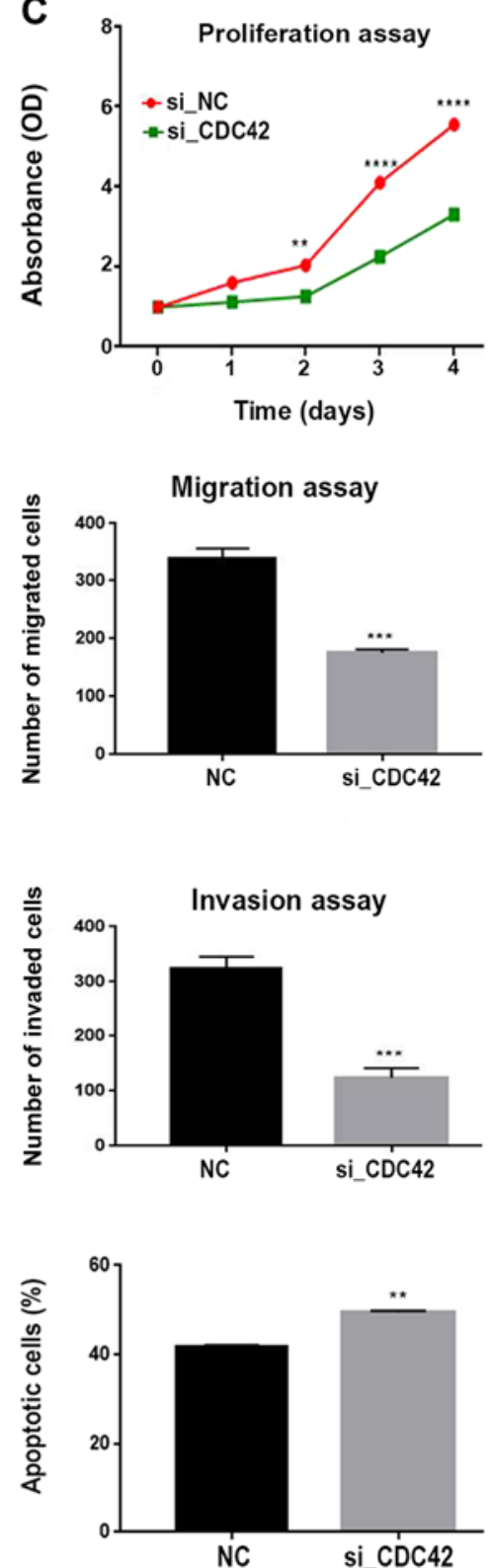

Annexin V-FITC

Figure 6. IQGAP3 silencing increases the sensitivity of ovarian cancer cells to olaparib and the regulatory role of CDC42 on IQGAP3. (A) Cell viability assay demonstrated increased sensitivity of olaparib in A2780 and HEY cells following IQGAP3 knockdown using two siRNAs. (B) Knockdown of $C D C 42$ by transient transfection. (C) $C D C 42$ silencing reduces HEY cell proliferation in a time-dependent manner. (D) Silencing of $C D C 42$ significantly reduces the migration and invasion in HEY cells. Magnification, x10. (E) Downregulation of $C D C 42$ increases apoptosis in HEY cells. ${ }^{* * *} \mathrm{P}<0.01 ;{ }^{* * * *} \mathrm{P}<0.001 ;{ }^{* * * * *} \mathrm{P}<0.0001$ vs. NC. IQGAP3, IQ motif containing GTPase Activating Protein 3; siRNA, small interfering RNA.

and tumorigenesis assays in nude mice demonstrated the decreased proliferative capacity of ovarian cancer cells when IQGAP3 was knocked down in vitro and in vivo.

Metastasis is a culmination of cancer cells gaining migratory and invasive abilities (51). Furthermore, distant metastasis at the time of diagnosis is one of the major obstacles negatively impacting the prognosis of ovarian cancer (52). The molecular mechanisms of metastasis in ovarian cancer are yet to be fully elucidated; however, EMT has been considered to be a potential contributing factor (52-54).

The present results suggested that IQGAP3 serves a substantial role in migration and invasion of ovarian cancer, and knocking down IQGAP3 reduced the metastatic potential. These findings were also observed in vivo, where fewer metastatic foci formed in the mice injected with IQGAP3-silenced cells compared with the control group. 
EMT is initiated by several EMT-inducing transcription factors (53-58). In the present study, it was found that several of the EMT-inducing factors were affected by alterations in the expression of IQGAP3, which suggests a pivotal role of $I Q G A P 3$ in the induction of EMT in ovarian cancer.

Several studies have reported that the PI3K/AKT/mTOR signaling pathway is a crucial pathway by which cancer cells exhibit increased proliferative and metastatic potential (59-64). This signaling pathway is involved in several fundamental processes in ovarian cancer, such as cell proliferation, survival, autophagy, transcription regulation and angiogenesis $(63,64)$. Therefore, to determine the mechanism underlying the effects of $I Q G A P 3$ in ovarian cancer, the effects of altering IQGAP3 gene expression of the PI3K/AKT/mTOR pathway were determined. Western blot analysis revealed a significant downregulation in the expression levels of $P I 3 K, \mathrm{p}-A K T$ and $\mathrm{p}-m T O R$ when $I Q G A P 3$ expression was knocked down. Thus, these results suggested that IQGAP3 may promote tumor progression and metastasis via the PI3K/AKT/mTOR signaling pathway.

Previous studies have shown that increased apoptosis may underlie decreased tumor growth, chemoresistance and metastasis in several types of cancer $(65,66)$. It has also been reported that IQGAP3 in certain types of cancer is closely associated with apoptosis (35). In the present study, it was demonstrated that the apoptotic potential of cells was increased when IQGAP3 expression was knocked down, and this may underlie the effects of IQGAP3 on tumor growth.

CDC42 is a member of the Rho family of GTPases, and is ubiquitously expressed (23). Moreover, $C D C 42$ participates in the regulation of cytoskeletal dynamics, cellular proliferation, motility, polarity and cytokinesis (67). Wang et al (28) also identified a direct interaction between IQGAP3 with $C D C 42$, and revealed IQGAP3 is an indispensable effector of CDC42-mediated cell proliferation. Furthermore, Xu et al (35) hypothesized that IQGAP3 may serve as an oncogene in pancreatic cancer by regulating the $C D C 42$ signaling pathway. Morgan et al (68) reported there was an interaction between IQGAP3 and CDC42 using immunoprecipitation assays. The results of the present study also demonstrated that knocking down IQGAP3 expression resulted in the downregulation of $C D C 42$ expression. Therefore, the role of $C D C 42$ in ovarian cancer cells was further investigated. It was found that knockdown of $C D C 42$ resulted in a significant decrease in proliferation, migration and invasion, and increased apoptosis in ovarian cancer cells. Thus, it was speculated that IQGAP3 may exert its function via modulation of $C D C 42$, but further studies are required to verify this hypothesis.

$P A R P$ serves a key role in the DNA damage response of the cell $(10,11,13)$. The $P A R P$ inhibitor olaparib has been recently approved by the FDA for the treatment of patients with ovarian cancer who harbor BRCA1/2 mutations (15). Moreover, $B R C A 1 / 2$ mutations are responsible for $18-40 \%$ of lifetime risk ovarian cancer cases in women, and $5-15 \%$ of all diagnosed cases harbor one of these mutations (69). Thus, the introduction of PARPi, such as olaparib, may improve the prognostic prospects of patients. However, this drug is not effective for all HGSOC cases (70). IQGAP3 is associated with olaparib drug sensitivity, and knockdown of IQGAP3 in the present study resulted in increased efficacy of olaparib, suggesting that the effectiveness of the treatment may be dependent upon specific clinical aspects. Additionally, the expression profiles of proteins involved in DNA damage response of cell, including ATM and CHK, were assessed. In the present study, there was a significant decrease in the expression levels of these proteins following IQGAP3 knockdown. Furthermore, similar effects were observed in Rad51, which possesses a crucial role in the homologous recombination repair of DNA (10). Therefore, it was hypothesized that downregulation of DNA repair factors may result in defective DNA repair in cells, thus increasing the sensitivity to PARPi.

However, further investigations focusing on the mechanistic role of IQGAP3 in proliferation and metastasis of ovarian cancer are required before IQGAP3 may be considered a diagnostic and prognostic marker, and as a potential therapeutic target for ovarian cancer. To the best of our knowledge, the present study was the first to report the role of IQGAP3 in the progression of HGSOC.

In conclusion, IQGAP3 exhibited oncogenic features in HGSOC. In addition, the expression of IQGAP3 was upregulated in HGSOC, and its expression was associated with a poor outcome in patients. However, more studies are required to further validate IQGAP3 as a prognostic marker and a therapeutic target for ovarian cancer.

\section{Acknowledgements}

The authors would like to acknowledge the contribution of Dr Kun Song from the Department of OB/GYN and Dr Ning Yang from the Department of Pathology at Qilu Hospital of Shandong University (Ji'nan, China), and Dr Shi Yan, Dr Rongrong Li and Dr Cunzong Yuan from the Key Laboratory of Gynecologic Oncology of Shandong (Ji'nan, China), who contributed greatly to the completion of this manuscript.

\section{Funding}

The present study was supported by the National Natural Science Foundation of China (grant nos. 81874107 and 81572554).

\section{Availability of data and materials}

All data generated or analyzed during this study are included in this published article.

\section{Authors' contributions}

SD, QZ and BK contributed to the conceptualization of the study. SD drafted the manuscript. SD, CQ, CS, ZZ and HW contributed to data acquisition, carried out the data analysis and revised the manuscript. QZ and BK were involved in analyzing the critical intellectual content and gave the final approval of the version to be published. All authors read and approved the final manuscript.

\section{Ethics approval and consent to participate}

Signed consents were collected from all the patients and the study was approved by Ethics Committee of Qilu hospital of Shandong University. Approval of Shandong University 
Animal Care and Use Committee was acquired for all the animal experiments.

\section{Patient consent for publication}

Not applicable.

\section{Competing interests}

The authors declare that they have no competing interests.

\section{References}

1. Siegel RL, Miller KD and Jemal A: Cancer statistics, 2019. CA Cancer J Clin 69: 7-34, 2019.

2. Cancer Stat Facts: Ovarian Cancer. 2019. https://seer.cancer. gov/statfacts/html/ovary.html.

3. Ozols RF: Systemic therapy for ovarian cancer: Current status and new treatments. Semin Oncol 33 (Suppl 6): S3-S11, 2006.

4. Karnezis AN, Cho KR, Gilks CB, Pearce CL and Huntsman DG: The disparate origins of ovarian cancers: Pathogenesis and prevention strategies. Nat Rev Cancer 17: 65-74, 2017.

5. Cho KR and Shih IeM: Ovarian cancer. Annu Rev Pathol 4 287-313, 2009.

6. Kurman RJ and Shih IeM: The origin and pathogenesis of epithelial ovarian cancer: A proposed unifying theory. Am J Surg Pathol 34: 433-443, 2010.

7. Bast RC Jr, Hennessy B and Mills GB: The biology of ovarian cancer: New opportunities for translation. Nat Rev Cancer 9: 415-428, 2009.

8. Seidman JD, Horkayne-Szakaly I, Haiba M, Boice CR Kurman RJ and Ronnett BM: The histologic type and stage distribution of ovarian carcinomas of surface epithelial origin. Int J Gynecol Pathol 23: 41-44, 2004.

9. Peres LC, Cushing-Haugen KL, Köbel M, Harris HR, Berchuck A, Rossing MA and Doherty JA: Invasive epithelial ovarian cancer survival by histotype and disease stage. J Natl Cancer Inst 111: 60-68, 2019.

10. Pilié PG, Tang C, Mills GB and Yap TA: State-of-the-art strategies for targeting the DNA damage response in cancer. Nat Rev Clin Oncol 16: 81-104, 2019.

11. AlHilli MM, Becker MA, Weroha SJ, Flatten KS, Hurley RM, Harrell MI, Oberg AL, Maurer MJ, Hawthorne KM, Hou X, et al: In vivo anti-tumor activity of the PARP inhibitor niraparib in homologous recombination deficient and proficient ovarian carcinoma. Gynecol Oncol 143: 379-388, 2016.

12. McGuire WP III and Markman M: Primary ovarian cancer chemotherapy: Current standards of care. Br J Cancer 89 (Suppl 3): S3-S8, 2003.

13. Pokhriyal R, Hariprasad R, Kumar L and Hariprasad G: Chemotherapy resistance in advanced ovarian cancer patients. Biomark Cancer 11: 1179299X19860815, 2019.

14. Moore K, Colombo N, Scambia G, Kim BG, Oaknin A, Friedlander M, Lisyanskaya A, Floquet A, Leary A, Sonke GS, et al: Maintenance olaparib in patients with newly diagnosed advanced ovarian cancer. N Engl J Med 379 $2495-2505,2018$

15. Kim G, Ison G, McKee AE, Zhang H, Tang S, Gwise T, Sridhara R, Lee E, Tzou A, Philip R, et al: FDA approval summary: Olaparib monotherapy in patients with deleterious germline BRCA-mutated advanced ovarian cancer treated with three or more lines of chemotherapy. Clin Cancer Res 21: 4257-4261, 2015

16. Briggs MW and Sacks DB: IQGAP proteins are integral components of cytoskeletal regulation. EMBO Rep 4: 571-574, 2003.

17. Weissbach L, Settleman J, Kalady MF, Snijders AJ, Murthy AE, Yan YX and Bernards A: Identification of a human rasGAP-related protein containing calmodulin-binding motifs. J Biol Chem 269: 20517-20521, 1994.

18. Hedman AC, Smith JM and Sacks DB: The biology of IQGAP proteins: Beyond the cytoskeleton. EMBO Rep 16: 427-446, 2015.

19. Swart-Mataraza JM, Li Z and Sacks DB: IQGAP1 is a component of Cdc42 signaling to the cytoskeleton. J Biol Chem 277: 24753-24763, 2002.
20. Sahai E and Marshall CJ: RHO-GTPases and cancer. Nat Rev Cancer 2: 133-142, 2002.

21. Tang Y, Olufemi L, Wang MT and Nie D: Role of Rho GTPases in breast cancer. Front Biosci 13: 759-776, 2008.

22. Erickson JW and Cerione RA: Multiple roles for Cdc42 in cell regulation. Curr Opin Cell Biol 13: 153-157, 2001.

23. Arias-Romero LE and Chernoff J: Targeting Cdc42 in cancer Expert Opin Ther Targets 17: 1263-1273, 2013.

24. Johnson M, Sharma M and Henderson BR: IQGAP1 regulation and roles in cancer. Cell Signal 21: 1471-1478, 2009.

25. Mataraza JM, Briggs MW, Li Z, Entwistle A, Ridley AJ and Sacks DB: IQGAP1 promotes cell motility and invasion. J Biol Chem 278: 41237-41245, 2003.

26. Schmidt VA, Chiariello CS, Capilla E, Miller F and Bahou WF: Development of hepatocellular carcinoma in Iqgap2-deficient mice is IQGAP1 dependent. Mol Cell Biol 28: 1489-1502, 2008.

27. Nojima H, Adachi M, Matsui T, Okawa K, Tsukita S and Tsukita S: IQGAP3 regulates cell proliferation through the Ras/ERK signalling cascade. Nat Cell Biol 10: 971-978, 2008.

28. Wang S, Watanabe T, Noritake J, Fukata M, Yoshimura T, Itoh N, Harada T, Nakagawa M, Matsuura Y, Arimura N and Kaibuchi K: IQGAP3, a novel effector of Rac1 and Cdc42, regulates neurite outgrowth. J Cell Sci 120: 567-577, 2007.

29. Yang Y, Zhao W, Xu QW, Wang XS, Zhang Y and Zhang J: IQGAP3 promotes EGFR-ERK signaling and the growth and metastasis of lung cancer cells. PLoS One 9: e97578, 2014.

30. Hu G, Xu Y, Chen W, Wang J, Zhao C and Wang M: RNA Interference of IQ motif containing GTPase-activating protein 3 (IQGAP3) inhibits cell proliferation and invasion in breast carcinoma cells. Oncol Res 24: 455-461, 2016.

31. Shi Y, Qin N, Zhou Q, Chen Y, Huang S, Chen B, Shen G and Jia H: Role of IQGAP3 in metastasis and epithelial-mesenchymal transition in human hepatocellular carcinoma. J Transl Med 15: $176,2017$.

32. Cao H, Wang Q, Gao Z, Xu X, Lu Q and Wu Y: Clinical value of detecting IQGAP3, B7-H4 and cyclooxygenase-2 in the diagnosis and prognostic evaluation of colorectal cancer. Cancer Cell Int 19: 163, 2019

33. Wu J, Chen Z, Cao H, Yu Z, Feng J, Wang K, Lu Q and Wu Y: High expression of IQGAP3 indicates poor prognosis in colorectal cancer patients. Int J Biol Markers 34: 348-355, 2019.

34. Yasui W, Sentani K, Sakamoto N, Anami K, Naito Y and Oue N: Molecular pathology of gastric cancer: Research and practice. Pathol Res Pract 207: 608-612, 2011.

35. Xu W, Xu B, Yao Y, Yu X, Cao H, Zhang J, Liu J and Sheng H: Overexpression and biological function of IQGAP3 in human pancreatic cancer. Am J Transl Res 8: 5421-5432, 2016.

36. Javadi S, Ganeshan DM, Qayyum A, Iyer RB and Bhosale P. Ovarian cancer, the revised FIGO staging system, and the role of imaging. AJR Am J Roentgenol 206: 1351-1360, 2016.

37. Birrer MJ, Johnson ME, Hao K, Wong KK, Park DC, Bell A, Welch WR, Berkowitz RS and Mok SC: Whole genome oligonucleotide-based array comparative genomic hybridization analysis identified fibroblast growth factor 1 as a prognostic marker for advanced-stage serous ovarian adenocarcinomas. J Clin Oncol 25: 2281-2287, 2007.

38. Mateescu B, Batista L, Cardon M, Gruosso T, de Feraudy Y, Mariani O, Nicolas A, Meyniel JP, Cottu P, Sastre-Garau X and Mechta-Grigoriou F: miR-141 and miR-200a act on ovarian tumorigenesis by controlling oxidative stress response. Nat Med 17: 1627-1635, 2011

39. Ferriss JS, Kim Y, Duska L, Birrer M, Levine DA, Moskaluk C, Theodorescu D and Lee JK: Multi-gene expression predictors of single drug responses to adjuvant chemotherapy in ovarian carcinoma: Predicting platinum resistance. PLoS One 7: e30550, 2012.

40. Lisowska KM, Olbryt M, Dudaladava V, Pamuła-Piłat J, Kujawa K, Grzybowska E, Jarzab M, Student S, Rzepecka IK, Jarzab B and Kupryjańczyk J: Gene expression analysis in ovarian cancer-faults and hints from DNA microarray study. Front Oncol 4: 6, 2014.

41. Tothill RW, Tinker AV, George J, Brown R, Fox SB, Lade S, Johnson DS, Trivett MK, Etemadmoghadam D, Locandro B, et al: Novel molecular subtypes of serous and endometrioid ovarian cancer linked to clinical outcome. Clin Cancer Res 14: 5198-5208, 2008.

42. Uehara Y, Oda K, Ikeda Y, Koso T, Tsuji S, Yamamoto S, Asada K, Sone K, Kurikawa R, Makii C, et al: Integrated copy number and expression analysis identifies profiles of Whole-arm chromosomal alterations and subgroups with favorable outcome in ovarian clear cell carcinomas. PLoS One 10: e0128066, 2015. 
43. Gyorffy B, Lánczky A and Szállási Z: Implementing an online tool for genome-wide validation of survival-associated biomarkers in ovarian-cancer using microarray data from 1287 patients. Endocr Relat Cancer 19: 197-208, 2012.

44. Livak KJ and Schmittgen TD: Analysis of relative gene expression data using real-time quantitative PCR and the 2(-Delta Delta C(T)) method. Methods 25: 402-408, 2001

45. Pokharel D, Roseblade A, Oenarto V, Lu JF and Bebawy M: Proteins regulating the intercellular transfer and function of P-glycoprotein in multidrug-resistant cancer. Ecancermedicalscience 11: 768, 2017.

46. Naora $\mathrm{H}$ and Montell DJ: Ovarian cancer metastasis: Integrating insights from disparate model organisms. Nat Rev Cancer 5: 355-366, 2005.

47. Campos SM and Ghosh S: A current review of targeted therapeutics for ovarian cancer. J Oncol 149362, 2010.

48. Hogberg T: Chemotherapy: Current drugs still have potential in advanced ovarian cancer. Nat Rev Clin Oncol 7: 191-193, 2010.

49. White CD, Khurana H, Gnatenko DV, Li Z, Odze RD, Sacks DB and Schmidt VA: IQGAP1 and IQGAP2 are reciprocally altered in hepatocellular carcinoma. BMC Gastroenterol 10: 125, 2010.

50. Wu K, Zhang X, Li F, Xiao D, Hou Y, Zhu S, Liu D, Ye X, Ye M, Yang $\mathrm{J}$, et al: Frequent alterations in cytoskeleton remodelling genes in primary and metastatic lung adenocarcinomas. Nat Commun 6: 10131, 2015.

51. Guan X: Cancer metastases: Challenges and opportunities. Acta Pharm Sin B 5: 402-418, 2015

52. Huang RY, Chung VY and Thiery JP: Targeting pathways contributing to epithelial-mesenchymal transition (EMT) in epithelial ovarian cancer. Curr Drug Targets 13: 1649-1653, 2012

53. Berx G, Raspe E, Christofori G, Thiery JP and Sleeman JP Pre-EMTing metastasis? Recapitulation of morphogenetic processes in cancer. Clin Exp Metastasis 24: 587-597, 2007.

54. Lamouille S, Xu J and Derynck R: Molecular mechanisms of epithelial-mesenchymal transition. Nat Rev Mol Cell Biol 15: 178-196, 2014.

55. Thiery JP and Sleeman JP: Complex networks orchestrate epithelial-mesenchymal transitions. Nat Rev Mol Cell Biol 7: 131-142, 2006

56. Barrallo-Gimeno A and Nieto MA: The Snail genes as inducers of cell movement and survival: Implications in development and cancer. Development 132: 3151-3161, 2005.

57. Hugo H, Ackland ML, Blick T, Lawrence MG, Clements JA, Williams ED and Thompson EW: Epithelial-mesenchymal and mesenchymal-epithelial transitions in carcinoma progression. J Cell Physiol 213: 374-383, 2007.
58. Peinado H, Olmeda D and Cano A: Snail, Zeb and bHLH factors in tumour progression: An alliance against the epithelial phenotype? Nat Rev Cancer 7: 415-428, 2007.

59. Cantley LC: The phosphoinositide 3-kinase pathway. Science 296: 1655-1657, 2002.

60. Fresno Vara JA, Casado E, de Castro J, Cejas P, Belda-Iniesta C and Gonzalez-Baron M: PI3K/Akt signalling pathway and cancer. Cancer Treat Rev 30: 193-204, 2004.

61. Willems L, Tamburini J, Chapuis N, Lacombe C, Mayeux P and Bouscary D: PI3K and mTOR signaling pathways in cancer: New data on targeted therapies. Curr Oncol Rep 14: 129-138, 2012.

62. McAuliffe P, Meric-Bernstam F, Mills GB and Gonzalez-Angulo A: Deciphering the role of PI3K/Akt/mTOR pathway in breast cancer biology and pathogenesis. Clin Breast Cancer 10 (Suppl 3): S59-S65, 2010.

63. Gasparri ML, Bardhi E, Ruscito I, Papadia A, Farooqi AA, Marchetti C, Bogani G, Ceccacci I, Mueller MD and Benedetti Panici P: PI3K/AKT/mTOR pathway in ovarian cancer treatment: Are we on the right track? Geburtshilfe Frauenheilkd 77: 1095-1103, 2017.

64. Mabuchi S, Kuroda H, Takahashi R and Sasano T: The $\mathrm{PI} 3 \mathrm{~K} / \mathrm{AKT} / \mathrm{mTOR}$ pathway as a therapeutic target in ovarian cancer. Gynecol Oncol 137: 173-179, 2015.

65. Wong RS: Apoptosis in cancer: From pathogenesis to treatment. J Exp Clin Cancer Res 30: 87, 2011.

66. Su Z, Yang Z, Xu Y, Chen Y and Yu Q: Apoptosis, autophagy, necroptosis, and cancer metastasis. Mol Cancer 14: 48, 2015.

67. Melendez J, Grogg M and Zheng Y: Signaling role of Cdc42 in regulating mammalian physiology. J Biol Chem 286: 2375-2381, 2011.

68. Morgan CJ, Hedman AC, Li Z and Sacks DB: Endogenous IQGAP1 and IQGAP3 do not functionally interact with Ras. Sci Rep 9: 11057, 2019.

69. Ramus SJ and Gayther SA: The contribution of BRCA1 and BRCA2 to ovarian cancer. Mol Oncol 3: 138-150, 2009.

70. Jiang X, Li X, Li W, Bai H and Zhang Z: PARP inhibitors in ovarian cancer: Sensitivity prediction and resistance mechanisms. J Cell Mol Med 23: 2303-2313, 2019.

This work is licensed under a Creative Commons Attribution-NonCommercial-NoDerivatives 4.0 International (CC BY-NC-ND 4.0) License. 